\title{
Vertical propagation of extratropical Rossby waves during the 1997-1998 El Niño off the west coast of South America in a medium-resolution OGCM simulation
}

\author{
Marcel Ramos, ${ }^{1,2}$ Boris Dewitte, ${ }^{3}$ Oscar Pizarro,,${ }^{4,5}$ and Gilles Garric ${ }^{6}$ \\ Received 9 December 2007; revised 18 May 2008; accepted 10 June 2008; published 26 August 2008.
}

[1] A medium-resolution ocean general circulation model (OGCM) simulation is used to investigate the subthermocline interannual variability in the eastern South Pacific. The focus is on isotherm vertical displacement variability associated with extratropical Rossby waves (ETRW) and their connection with equatorial Kelvin waves (EKW). The WKB theory is used to interpret the modeled subsurface variability. The analysis reveals vertical propagation of energy associated with the 1997-1998 El Niño near the coast at various latitudes. Consistent with theory, WKB raypaths are steeper southward and do not extend more than $\sim 600 \mathrm{~km}$ from the coast at $\sim 2000 \mathrm{~m}$ depth. A vertical mode decomposition of model variability showed that vertical propagation mostly involves the first three baroclinic modes. The vertical isotherm displacements along the raypaths, associated with the downwelling EKW of the 1997-1998 El Niño, are negative (rising isotherms) and peak (minimum isotherm) as El Niño reverses to La Niña conditions. The relationship between vertical propagation of ETRW and equatorial variability is interpreted in the light of EKW sequence. The evolution of the vertical isotherm displacements along the raypath at extratropical latitudes is controlled by the vertical structure of the EKW. As El Niño develops, high-order baroclinic mode contributions to the EKW progressively increase, leading to the dominance of finer vertical scales of variability along the coast, triggering the vertical propagation of ETRW. This mechanism of connection between equatorial variability and subsurface variability at the extratropical latitudes illustrates how sensitive the ETRW characteristics in the eastern South Pacific are to equatorial forcing.

Citation: Ramos, M., B. Dewitte, O. Pizarro, and G. Garric (2008), Vertical propagation of extratropical Rossby waves during the 1997-1998 El Niño off the west coast of South America in a medium-resolution OGCM simulation, J. Geophys. Res., 113, C08041, doi:10.1029/2007JC004681.

\section{Introduction}

[2] Oceanic variability along the western coast of South America is influenced by equatorial Kelvin waves (EKW) on a variety of timescales, from intraseasonal [Shaffer et al., 1997, 1999] and seasonal [Pizarro et al., 2002; Ramos et al., 2006] to interannual [Pizarro et al., 2001, 2002; Vega et al., 2003] and interdecadal [Montecinos et al., 2007]. Coastal-trapped Kelvin waves originating from the equator can propagate along the coast, modify the stability of the regional current system, and trigger extratropical Rossby

\footnotetext{
${ }^{1}$ Programa de Postgrado en Oceanografía, Departamento de Oceanografía, Universidad de Concepción, Concepción, Chile.

${ }^{2}$ Centro de Estudios Avanzados en Zonas Áridas, Facultad de Ciencias del Mar, Universidad Católica del Norte, Coquimbo, Chile.

${ }^{3}$ LEGOS, Toulouse, France.

${ }^{4}$ Departamento de Geofísica, Universidad de Concepción, Concepción, Chile.

${ }^{5}$ COPAS, Universidad de Concepción, Concepción, Chile.

${ }^{6}$ MERCATOR-OCEAN, Ramonville St. Agne, France.

Copyright 2008 by the American Geophysical Union. 0148-0227/08/2007JC004681
}

waves (ETRW) equatorward of the critical latitude [Clarke and Shi, 1991]. As a matter of fact, the eastern South Pacific is a place of marked ETRW activity [Chelton and Schlax, 1996; Stammer, 1997] which, because of the beta effect, propagates more slowly as latitude increases. Thus, whereas the observed phase speed value at $\sim 10^{\circ} \mathrm{S}$ is $24.4 \mathrm{~cm} \mathrm{~s}^{-1}$ [Chelton and Schlax, 1996], the ETRW propagation is ten times slower at $\sim 30^{\circ} \mathrm{S}$, making it much more difficult to observe and identify given the likely impact of nonlinearities and dissipation on its characteristics. On interannual timescales, theory predicts that ETRW can radiate at any latitude along the coast. Indeed, westward propagation of sea level anomalies can be clearly observed in the eastern South Pacific on interannual timescales [Wang et al., 1998; Fu and Chelton, 2001; Pizarro et al., 2002; Vega et al., 2003]. For example, Figure 1 displays the 2-D spectrum for sea level anomalies from altimetric data (see section 2.2) at $20^{\circ} \mathrm{S}$ and $30^{\circ} \mathrm{S}$. The correspondence between the theoretical dispersion curves (for the standard and the extended theories [cf. Fu and Chelton, 2001; Killworth and Blundell, 2004]) for first-mode baroclinic ETRW and the zone of maximum amplitude indicates that ETRW make a signifi- 

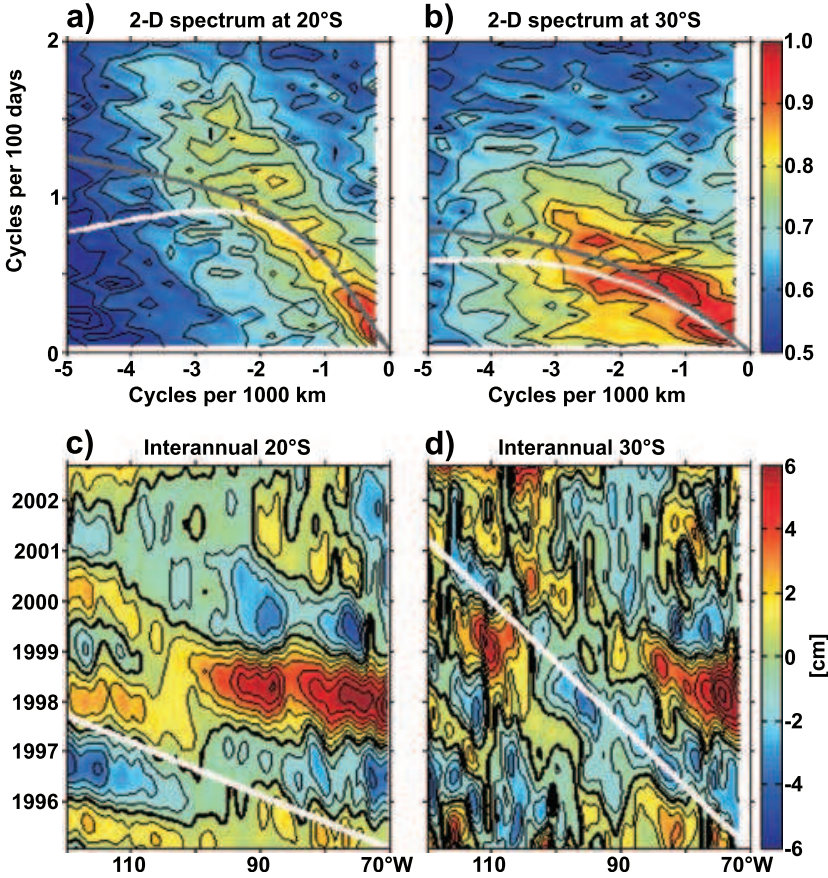

Figure 1. Two-dimensional spectra for the sea level height (SLH) anomalies from TOPEX/Poseidon, ERS-1/2, and Jason-1 data sets (TPERSJ) at (a) $20^{\circ} \mathrm{S}$ and (b) $30^{\circ} \mathrm{S}$; each spectrum was calculated from the coast to $160^{\circ} \mathrm{W}$ (in arbitrary units). Longitude-time diagrams of the interannual SLH anomalies (in $\mathrm{cm}$ ) from TPERSJ at (c) $20^{\circ} \mathrm{S}$ and (d) $30^{\circ} \mathrm{S}$. The thick lines in the spectra are the dispersion curves for (bottom white lines) the standard theory and (top gray lines) the extended theory for the first-mode baroclinic extratropical Rossby waves (ETRW). The extended theory refers to the formalism taking into account the effect of baroclinic mean horizontal current in a flat bottom ocean [Fu and Chelton, 2001; Killworth and Blundell, 2004]. A geostrophic zonal velocity profile was estimated by using climatological temperature-salinity data from Boyer et al. [2005] (compare with the paper by Ramos et al. [2006] for more details). In Figures 1c and 1d the white lines represent the (standard) theoretical phase speed for the first vertical mode of a long ETRW.

cant contribution to nearshore variability in these regions. Note that besides the clear difference in phase speed, the 2-D diagram at $20^{\circ} \mathrm{S}$ exhibits a better coherency with the theoretical dispersion curves than the one at $30^{\circ} \mathrm{S}$, with its patchier energy distribution. It also indicates that the ETRW amplitude drops sharply as it propagates westward from the coast, suggesting dissipation processes at work. For instance, the amplitude of the strong downwelling ETRW associated with the 1997-1998 El Niño (Figures 1c and 1d) decreased by a factor of $\sim 3(\sim 3.5)$ from the coast to $85^{\circ} \mathrm{W}$ at $20^{\circ} \mathrm{S}\left(30^{\circ} \mathrm{S}\right)$. Although multimode linear Rossby wave models in which dispersion induced by the Rossby radius of deformation varying with latitude is neglected (i.e., the Rossby wave equation can be resolved independently at each latitudes) have been very useful in interpreting many observed propagating characteristics of the ETRW south of about $10^{\circ} \mathrm{S}$ [Vega et al., 2003; Ramos et al., 2006], they cannot account properly for this westward decrease in amplitude of the ETRW variability, which can be caused by nonlinear processes. For the Northern Hemisphere, Qiu et al. [1997] first evoked the possibility that such decay could be due to turbulent viscous dissipation. Building upon the results of Jones [1978], LaCasce and Pedlosky [2004] recently proposed a nonlinear mechanism explaining the dissipation process directly in terms of baroclinic instability of the Rossby wave itself and describe the dissipation and confinement of the Rossby wave as the breakdown of the wave as it transfer energy to a small-scale eddy field. In fact, linear dispersion of Rossby waves associated to the latitudinal variations of the Coriolis parameter is also a source of dissipation. Indeed, it was first shown by Schopf et al. [1981] that the linear dispersion generates a caustic line that originates from the critical latitude. Such caustic lines define a boundary across which boundary-driven Rossby waves cannot propagate. Since linear dispersion becomes increasingly important away from the equator, it is a potential mechanism for explaining the surface dissipation of the extratropical Rossby waves. However, the theoretical results of Schopf et al. [1981] suggest that dispersion remains weak for the low-frequency variability and within $\sim 20^{\circ}$ near the western boundary (see Schopf et al. [1981, Figure 3] for the annual cycles). Other relevant linear mechanisms that may impact the Rossby wave characteristics include the coupling of the Rossby waves to bottom topography [Killworth and Blundell, 1999] or the effects of mean vertical shear [Schopf et al., 1981; Killworth et al., 1997; deSzoeke and Chelton, 1999; Colin deVerdiere and Tailleux, 2005] or bottom roughness [Tailleux and McWilliams, 2001]. Within the linear framework, another process to be considered when interpreting the surface signature of the ETRW is the vertical propagation of energy that involves the constructive contribution of a certain number of baroclinic modes [McCreary, 1984; Gent and Luyten, 1985]. In the equatorial regions, vertical energy propagation was investigated from observations [Kessler and McCreary, 1993] and a model simulation [Dewitte and Reverdin, 2000] in order to explain the characteristic of the reflected equatorial Rossby wave at the eastern boundary on a seasonal timescale. This process is often cited as being responsible for the decreased amplitude of long Rossby waves as they propagate offshore. It may also contribute to the modulation of the deep current and, in irregular topographic areas, could participate in the peculiarities of the deep circulation through bottom reflection of the vertically propagating wave and enhancing mixing.

[3] To the best of the authors' knowledge, there have been very few studies that document the vertical propagation of Rossby waves in the literature for the extratropical latitudes. The study by Yang [2000] implicitly addressed this issue within an idealized framework by proposing analytical solutions of the evolution of a long planetary wave packet in response to various forcing function. On the basis of the ocean general circulation model (OGCM) simulation of the South Eastern Pacific, Dewitte et al. [2008] documented the vertically propagating variability at seasonal timescale and show evidence of energy trajectories associated to extratropical Rossby wave that roughly follow the theoretical WKB raypath. In this study, the WKB formalism is extended to the ETRW for interannual time- 
scales, focusing on the strong 1997-1998 El Niño event. The WKB technique is valid provided that the scale of the spatial variations is large compared with the wavelength of the waves, which is the case here as will be checked a posteriori.

[4] Because of the scarcity of in situ data in the region, which prevents resolving the fine vertical scales of temperature on interannual timescales in the subthermocline, the outputs of a $1 / 4^{\circ}$ resolution OGCM simulation are used. The linear formalism is used as a background framework to interpret the model data along with the results of a vertical mode decomposition of the simulated variability, which extends previous works based on simple model simulations [Vega et al., 2003; Ramos et al., 2006]. Of particular interest is the nearshore variability associated with the large 19971998 El Niño. The motivations for focusing on this particularly strong event are related to the fact that (1) it may ease the identification of vertically propagating energy that involves the slow high-order baroclinic mode ETRW, and (2) it was well documented in the literature for the equatorial region [McPhaden, 1999], in particular with respect to its vertical structure variability [Dewitte et al., 2003], providing material for interpreting the results presented herein.

[5] The paper is organized as follows: Section 2 presents the model, the data set, and the methods that are used to diagnose vertical propagation. Section 3 is devoted to a comparison of the model sea level variability with the altimetric data as derived from the TOPEX/POSEIDON and ERS1/2 satellites. Section 4 investigates the vertically propagating energy in the model and its connection with equatorial variability. Finally, Section 5 discusses the main results and presents some concluding remarks.

\section{Model, Data, and Methods}

\subsection{Model Configuration and Forcing}

[6] In this study, we use an ocean general circulation model simulation for 1992-2001 of the MERCATOR global ocean model. The eddy-permitting $1 / 4^{\circ}$ global MERCATOR model is based on the primitive equations global general ocean circulation model OPA, written by Madec et al. [1998] and developed at the LOCEAN (CNRS/ IRD laboratory). The horizontal resolution is based on an ORCA-type grid [Madec and Imbard, 1996] and becomes finer with increasing latitudes: $\sim 27.75 \mathrm{~km}$ at the equator and $\sim 13.8 \mathrm{~km}$ at $60^{\circ} \mathrm{S}$ or $60^{\circ} \mathrm{N}$. This configuration has 46 vertical z-levels $(6 \mathrm{~m}$ at the surface and $250 \mathrm{~m}$ at the bottom). This $1 / 4^{\circ}$ configuration is based on the 8.2 version of OPA, with a free surface formulation, isopycnal diffusion for temperature and salinity, biharmonic horizontal viscosity with an added harmonic operator in the equatorial $\left(1-3^{\circ}\right.$ latitude) upper layers for the dynamics, nonlinear bottom boundary friction, free slip lateral boundary condition, a 1.5 turbulent eddy kinetic energy closure scheme, and a convection parameterized by the enhanced vertical mixing coefficient.

[7] The bathymetry is derived from the Etopo2 database of NGDC (National Geophysical Data Center), which is a combination of the satellite-based bathymetry [Smith and Sandwell, 1997] and IBCAO in the Arctic [Jakobsson et al., 2000]. It has been merged with the BEDMAP data [Lythe et al., 2001] beyond $72^{\circ} \mathrm{S}$ in the Antarctic. A relaxation of 40 $\mathrm{W} \mathrm{m}{ }^{-2}$ is applied toward the real-time, global, sea surface temperature daily analysis (http://polar.ncep.noaa.gov/sst/ oper/Welcome.html) and the Levitus et al. [1998] monthly climatology of sea surface salinity. Freshwater discharge from continents is represented by 120 river mouth inflows (with a total of $0.63 \mathrm{~Sv}$ ). Daily surface atmospheric conditions are given by the ECMWF (European Center for Medium Range Weather Forecast) reanalysis project ERA40 [Uppala et al., 2005]. The experiment started at rest from 1 January 1992 with the prescribed conditions for temperature and salinity derived from the Levitus et al. [1998] data set for middle and low latitudes. For high latitudes, we chose the PHC2.1 climatology [Steele et al., 2001] and, for the Mediterranean Sea, the Medatlas climatology [Jourdan et al., 1998]. The year 1992 was integrated three times before launching the interannual experiment over the 1993-2001 period. The simulation used (POG05B) is hereafter referred to as MERCATOR (see the paper by Derval et al. [2005] for more details). There is no assimilation of data in this experiment.

\subsection{Data Set}

[8] In order to validate the propagation properties of the simulation, sea level height (SLH) anomalies were obtained from TOPEX/Poseidon, ERS-1/2, and Jason-1 data sets (TPERSJ) from October 1992 to January 2005. The SLH global maps result from an optimal interpolation of combined altimetry data on a Mercator $1 / 3^{\circ}$ grid every week. Resolutions in kilometers in latitude and longitude are thus identical and vary with the cosine of latitude (e.g., from $37 \mathrm{~km}$ at the equator to $18.5 \mathrm{~km}$ at $\left.60^{\circ} \mathrm{N} / \mathrm{S}\right)$. SLH anomalies are computed with respect to a 7-year mean (January 1993 to January 1999). A detailed description of these data can be found in the paper by Ducet et al. [2000] and at http:// www.aviso.oceanobs.com. In addition, global-scale gridded data of temperature and salinity from the World Ocean Atlas [Boyer et al., 2005] were used to estimate the theoretical phase speeds and the dispersion curves of subtropical Rossby waves, using standard and extended theory [Killworth et al., 1997; Fu and Chelton, 2001; Killworth and Blundell, 2004].

\subsection{Methods}

[9] The methodology adopted in this study follows Kessler and McCreary [1993] to a large extent. It uses the WKB raypath theory as a tool for interpreting wave features identified in vertical isotherm displacements in the equatorial waveguide. The theoretical background of the WKB raypath theory and the range of validity of the assumptions made are generalized for the extratropical latitudes and the "adapted" formalism is presented in Appendix A. It was also checked that working with vertical isopycnal displacement instead of vertical isotherm displacement leads to comparable results than the one presented in this paper. According to WKB theory, vertical displacements $\zeta$ should scale as $N^{-1 / 2}$ and, therefore, should vary smoothly along raypaths below the thermocline. Raypaths correspond to the path of the energy flux (u.p, v.p, w. $p)$ where $(u, v, w)$ is the velocity vector and $p$ the pressure field [Eliassen and Palm, 1960]. This flux should be averaged over at least one cycle of the variability mode 
of interest. If there is only one raypath present (i.e., monofrequency variability) and linear theory applies, the phase of the signal in vertical displacement should be constant along the raypath and the energy flux should be parallel to it. In practice, however, variability is multifrequency, signals originating from various areas interfere, and the simulation is nonlinear; hence, the raypath concept should only be viewed as a diagnostic tool to interpret the data. Here, since we focus on the 1997-1998 El Niño and cannot extract a single dominant interannual frequency representative of this event over the relatively short record of the simulation, complex empirical orthogonal functions (CEOF) following the method of Horel [1984] are used to evaluate the spatial patterns and temporal evolution of the dominant modes of variability on interannual timescales during this period. Several studies have used CEOF to analyze the interannual variability in observations and models [e.g., White et al., 1998; Leonardi et al., 2002]. This method shares the characteristics of standard EOF analysis but, in addition, allows for the detection of propagating features in the data. Generally, CEOF analysis is applied to SLH anomalies to capture interannual propagative features contained therein. In our case, the results indicate that the first CEOF mode explained a major part of the variance in all the analyzed fields (for sea level, the percentage of explained variance is always greater than $90 \%$ ), which led us to use the reconstructed fields from the dominant CEOF mode instead of a particular harmonic (which grasps less variance than the CEOF mode) for inferring from the energy flux.

[10] In order to focus on interannual anomalies, all time series (of both altimetry data and simulated fields) were previously low-pass filtered with a cosine-Lanczos filter (50\% power at 18.4 months) after extracting the seasonal cycle. The seasonal cycle was derived by least squares fit of the time series to the annual and semiannual harmonics. Also, following Horel [1984], one tenth of each time series at the beginning and the end of record were deleted to avoid end effects by the Fourier transform.

[11] In addition, a vertical mode decomposition of the model variability ( $p$ and $\zeta$ ) was performed using the baroclinic mode structure functions as derived from the model mean stratification following the procedure of Dewitte et al. [1999]. Such analysis is used to interpret the subsurface variability as derived from the vertical isotherm displacements, since vertically propagating waves involve the contribution of the most energetic high-order baroclinic modes. It also acts as a consistency check for the interpretation of the model variability in terms of ETRW. In this analysis, two critical assumptions were made. First, linearization was assumed to be appropriate. This requires small interface deviations in comparison with the mean layer thicknesses and is probably a valid approximation for interannual timescales. Second, it was assumed that the WKB approximation could be made (implying a slowly varying background flow) allowing the analysis to be done independently at each location. Comparisons of WKB solutions with "true" solutions have shown that the WKB approximation usually breaks down over regions of strong topographic curvatures [Tailleux and McWilliams, 2002; Tailleux, 2004]. Despite that long-wavelength Rossby wave considered here are rather far from the coast and that the ocean is deep all along the coast, it is worth noting that the assumption of smooth topography, necessary to use WKB, is hardly satisfied in the actual ocean. Whereas the presence of topographic slopes does impact the local baroclinic modes and their phase speeds, in a basin-wide average, topographic variations do not influence the overall propagation characteristics of long-wavelength Rossby waves [Killworth and Blundell, 1999].

\section{Extratropical Rossby Wave Characteristics}

[12] As a first step, the model sea level variability (root mean square) is compared to the altimetric data (Figure 2). The comparison reveals an overall similar pattern over the study region with maximum variability in the equatorial band and a sharp southward decrease near $10^{\circ} \mathrm{S}$ that is more marked in the model than in the observations. Compared to the TPERSJ data, however, the model lacks variability in the equatorial region, which is believed to be due to the addition of Laplacian diffusion (harmonic operator with a coefficient of $\left.10^{11} \mathrm{~m}^{2} \mathrm{~s}^{-1}\right)$ in the $\left(3^{\circ} \mathrm{S}-3^{\circ} \mathrm{N}\right)$ latitudinal band (see Derval et al. [2005] for more details). The model also shows weaker variability south of $3^{\circ} \mathrm{S}$ than do the observations. This lack of energy is certainly due to the medium resolution used in this configuration that cannot fully resolve all the observed eddy activity.

[13] With these model flaws in mind, we now focus on the simulated propagating characteristics. Figure 3 displays the $\mathrm{CEOF}$ dominant mode (i.e., the first CEOF mode) obtained from the model sea level and the altimetric data. Observed and model fields were first low-pass filtered before performing the CEOF analysis. Note that an important characteristic for interannual oceanic Rossby waves is their beta refraction pattern resulting from the decrease in westward phase speed as the inverse square of latitude in accordance with linear theory [e.g., Chelton and Schlax, 1996; White et al., 1998]. At this point, it is interesting to note that such process may explain the spatial pattern of the interannual variability of the sea level in the region, which is well represented by CEOF analysis [White et al., 1998]. Figure 3 indicates that the model is rather skilful in simulating the basin propagating mode. First, the spatial patterns of amplitude and phase for the model and the observations are comparable. Spatial correlations between the model and observations reach 0.98 and 0.86 for amplitude and phase, respectively, excluding the region south of a line going from $10^{\circ} \mathrm{S}, 140^{\circ} \mathrm{W}$ to $30^{\circ} \mathrm{S}, 75^{\circ} \mathrm{W}$, which corresponds to the region of low-ETRW variability amplitude (see Figure 2). Second, the associated time series for the model and the observations are highly correlated $(\mathrm{r}=$ 0.95). Furthermore, the phase maps reveal westward propagations south of $\sim 10^{\circ} \mathrm{S}$. North of $10^{\circ} \mathrm{S}$, the CEOF extracts the slow propagating coupled mode associated with the 1997-1998 El Niño. Figure 3b also displays the temporal evolution of the phase, which reveals the existence of quasiperiodicity in the analyzed fields; a dominant period of $\sim 3.7$ years is found for the first CEOF mode in both the model and the observations.

[14] Figure 4 presents the recomposed sea level signal from the dominant CEOF mode at various latitudes for the model and observations. The results of the vertical mode decomposition of the pressure anomaly obtained from the 
a)

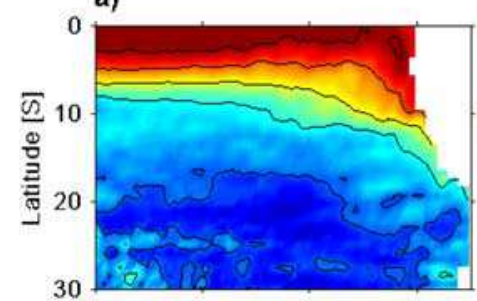

c)

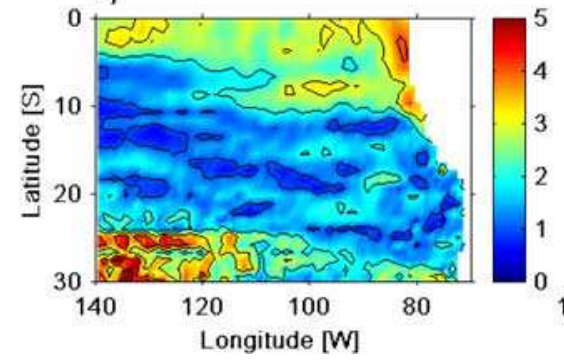

b)

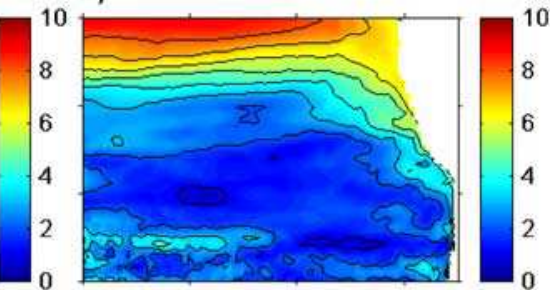

d)

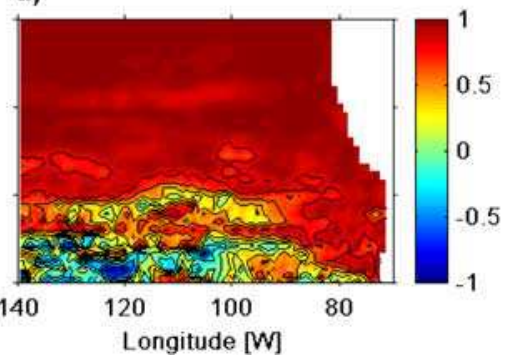

Figure 2. Eastern South Pacific study area. Root mean square (in $\mathrm{cm}$ ) of the interannual SLH anomalies from (a) TPERSJ and (b) MERCATOR model. (c) Root mean square (in $\mathrm{cm}$ ) of the differences between the model and the observations. (d) Temporal correlations between model and the observed SLH anomalies.

MERCATOR model are also displayed (Figure 4, bottom); these represent the summed-up contribution of baroclinic modes 1 to 3 . It is interesting to note that the results of the vertical mode decomposition account for a large fraction of the sea level variability, which provides a consistency check for the interpretation of the model variability in terms of propagating ETRW. The contribution of the first three baroclinic modes to the sea level variability account for
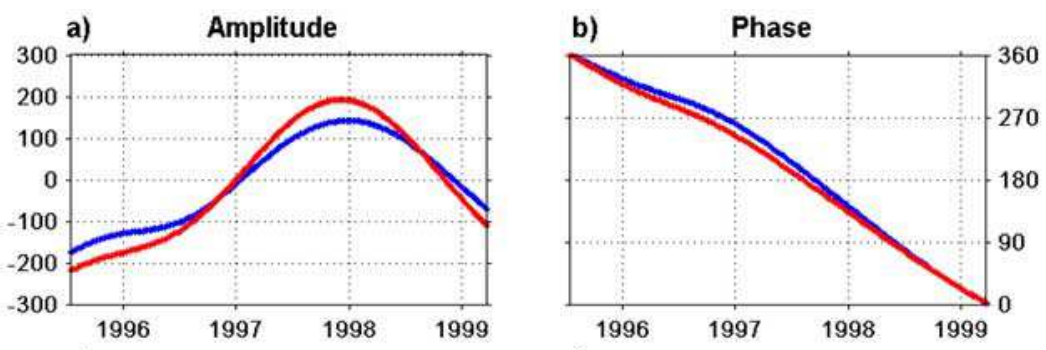

c)
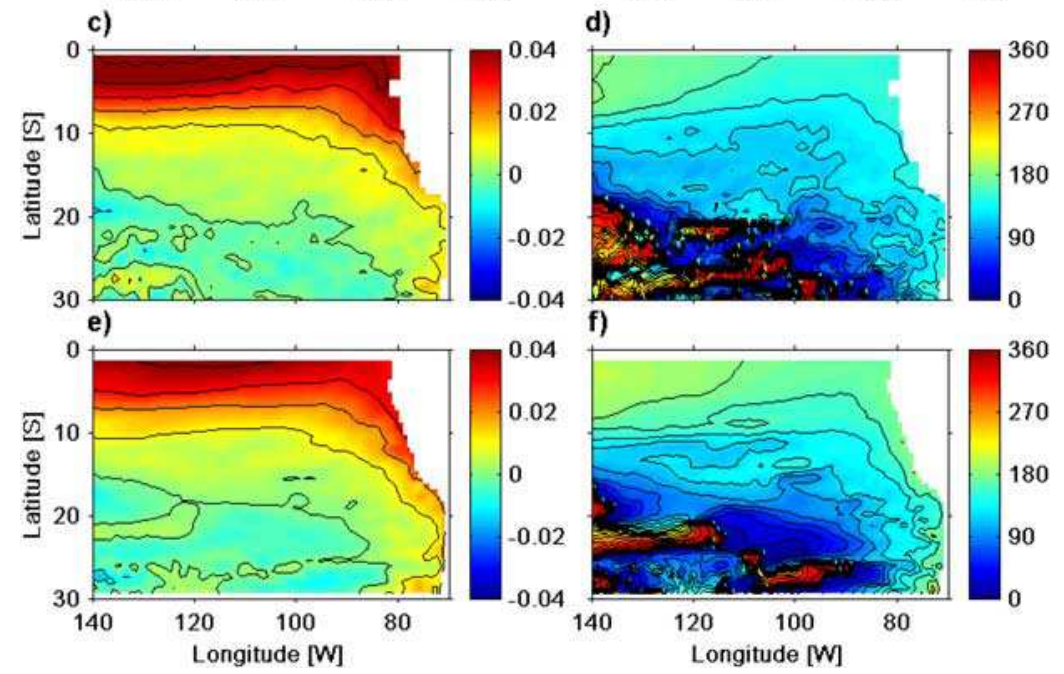

Figure 3. First complex empirical orthogonal functions (CEOF) mode of the interannual SLH anomalies from TPERSJ and MERCATOR model. Demeaned time series of (a) real amplitudes and (b) phases. The blue line is used for MERCATOR. The red line is used for TPERSJ. Spatial patterns of (c) real component and (d) its phase for TPERSJ. (e and f) Same as Figures 3c and 3d but for MERCATOR. The amplitudes are in arbitrary units, and the phases are in degrees. The explained variances by the first CEOF mode for TPERSJ and MERCATOR are 95\% and 93\%, respectively. 


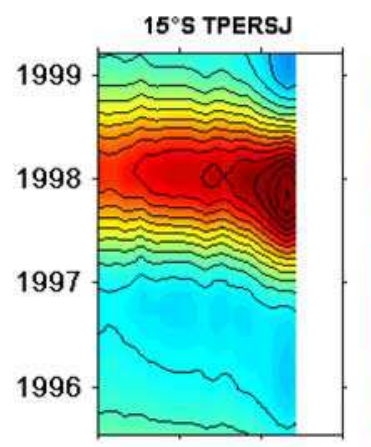

$15^{\circ} \mathrm{S}$ MERCATOR

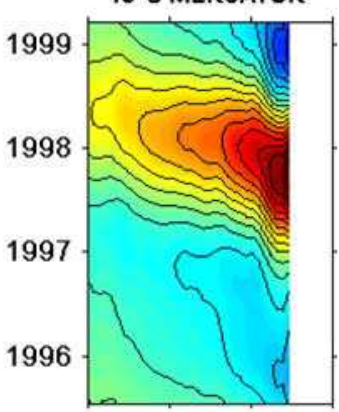

Modes 1 to 3

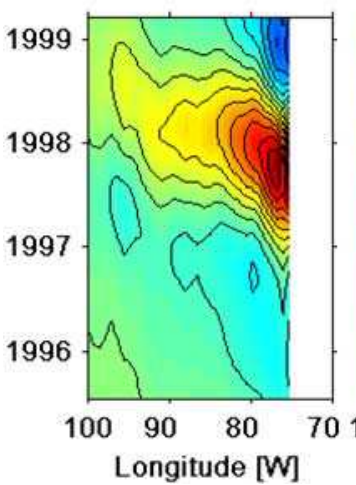

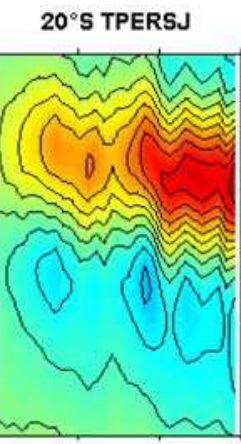

$20^{\circ} S$ MERCATOR

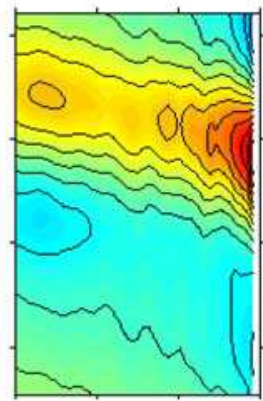

Modes 1 to 3

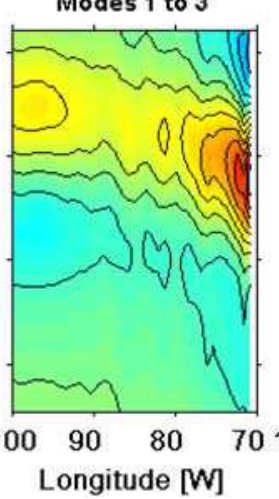

$25^{\circ} \mathrm{S}$ TPERSJ

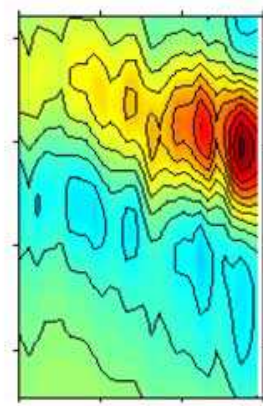

$25^{\circ} \mathrm{S}$ MERCATOR

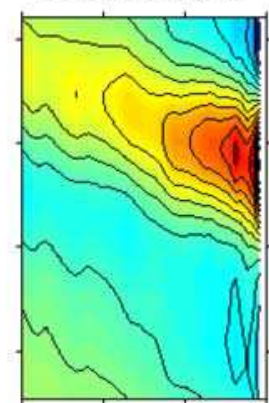

Modes 1 to 3

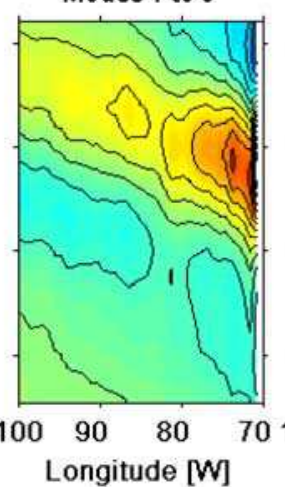

30'S TPERSJ

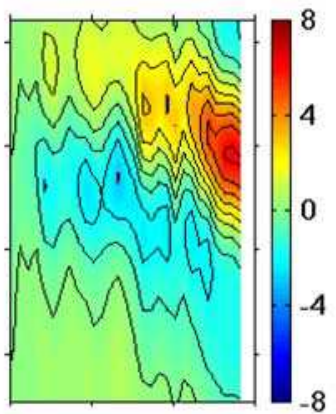

30'S MERCATOR

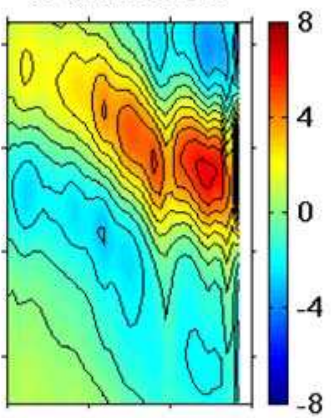

Modes 1 to 3

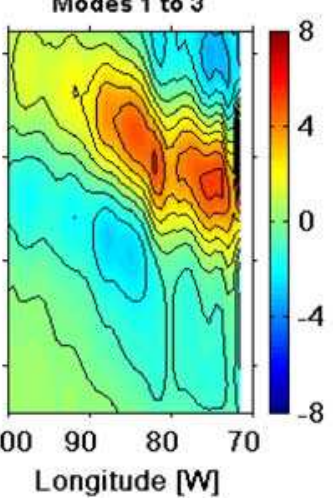

Figure 4. Longitude-time diagrams of the interannual SLH anomalies reconstructed from the first CEOF mode at different latitudes (in $\mathrm{cm}$ ). (top) Results from TPERSJ. (middle) Results from MERCATOR. (bottom) Similar CEOF results applied to the SLH anomalies estimated from the first three baroclinic modes. The explained variance for the first CEOF mode was $95 \%$ for TPERSJ, $93 \%$ for MERCATOR and $94 \%$ for the lower three baroclinic modes.

$69 \%, 64 \%, 78 \%$, and $83 \%$ of the variance of the total sea level variability at $15^{\circ} \mathrm{S}, 20^{\circ} \mathrm{S}, 25^{\circ} \mathrm{S}$, and $30^{\circ} \mathrm{S}$, respectively. The associated dominant CEOF mode explained as much as $94 \%$ of the variance (versus $93 \%$ for the "total" sea level). The comparison between the model results and the observations indicates that the propagation characteristics of the interannual ETRW during the 1997-1998 El Niño event are comparable. In particular, an energetic downwelling ETRW originates from the coast in the second half of 1997 at each latitude. The amplitude of the ETRW decreases westward more in the north than in the south in both the model and the observations, although the decay rate is larger in the model. A time associated with the decay rate $\mathrm{r}$ (assuming a Rayleigh-type friction) was estimated by fitting an exponential curve $[\exp (-\mathrm{rx} / \mathrm{c})]$ to the root mean square $(\mathrm{RMS})$ at each zonal section (for a distance of $\sim 2000 \mathrm{~km}$ from coast). An estimate of phase speed c given by the Radon transform from each longitude-time diagram is also used [e.g., Cipollini et al., 2000]. Phase speeds lead to values comparable to that estimated by Chelton and Schlax [1996]. The results are reported in Table 1. They indicate that the model tends to overestimate dissipation in the northern part of the domain, which may be due to a number of reasons. These include the absence of air-sea feedback in the model (since it is a forced simulation), a process likely to impact the characteristics of the ETRW [White et al., 1998; White, 2000] and the relatively low resolution of the model, which prevents simulating accurate coastal upwelling impacting the mean stratification near the coast and, thereby, the characteristics of the ETRW. Note, however, that at $25^{\circ} \mathrm{S}$ and $30^{\circ} \mathrm{S}$, comparable values of decay time are derived for the model and the observations. The values quantify the surface signature of the vertically propagating energy of the ETRW, 
Table 1. Decay Time (in Years) for TPERSJ Observations and MERCATOR Model at Various Latitudes (See Text) ${ }^{\mathrm{a}}$

\begin{tabular}{cccc}
\hline Latitude $\left({ }^{\circ} \mathrm{S}\right)$ & TPERSJ & MERCATOR & $\begin{array}{c}\text { Modes 1 to 3 } \\
\text { From MERCATOR }\end{array}$ \\
\hline 15 & 3.0 & 1.1 & 0.8 \\
20 & 2.2 & 1.4 & 1.1 \\
25 & 1.8 & 1.1 & 1.1 \\
30 & 2.2 & 1.9 & 1.9 \\
\hline
\end{tabular}

${ }^{\mathrm{a}}$ TPERSJ, TOPEX/Poseidon, ERS-1/2, and Jason-1 data sets.

a process that is investigated in the following section from the model outputs.

\section{Vertically Propagating Energy}

\subsection{Consistency With WKB Raypath Theory}

\subsubsection{Isotherm Vertical Displacement}

[15] We use two different products to analyze vertical energy propagation. The first one is computed following Kessler and McCreary [1993]; isotherm vertical displacements $\zeta=\mathrm{T} /(\partial \bar{T} / \partial z)$ are derived from the simulated temperature field (T) interpolated vertically on a $5 \mathrm{~m}$ grid using 1-D cubic splines. The second product is obtained on the basis of the above displacements, but they are then projected on the baroclinic mode structures for vertical velocity and the contribution of the first three baroclinic modes are derived [e.g., Dewitte et al., 1999]. The dominant CEOF modes at $20^{\circ} \mathrm{S}$ for both products are displayed in Figure 5. The theoretical WKB raypath (see equation (A5)) for $\omega=2 \pi / 3.7 \mathrm{a}^{-1}$ (where 3.7 years is the dominant period of the first CEOF mode for sea level, cf. Figure $3 b$ ) and c = $1.39 \mathrm{~m} \mathrm{~s}^{-1}$ ( $\mathrm{c}$ is the zonally averaged phase speed value for the second baroclinic mode as derived from the vertical mode decomposition of the mean stratification) is plotted for a starting point at the coast at $\sim 390 \mathrm{~m}$.

[16] The zonal section for the amplitude of the isotherm displacements suggests two domains separated by a slanted line extending roughly from the coast at $400 \mathrm{~m}$ to the west up to $1500 \mathrm{~m}$ (Figures $5 \mathrm{c}$ and $5 \mathrm{~d}$ ). Above and to the west of this line, the maximum amplitude is found within the thermocline where vertical changes in density are abrupt and WKB theory is not expected to apply. Below, the zone of maximum amplitude is located around the WKB raypath and the phase lines are approximately parallel, with the phase propagating upward and westward, and the slope more steeply downward at depth, where stratification is weaker. Comparable features are observed for the summedup (baroclinic modes 1 to 3 ) contribution to isotherm vertical displacements (Figures $5 \mathrm{e}$ and $5 \mathrm{f}$ ). The agreement
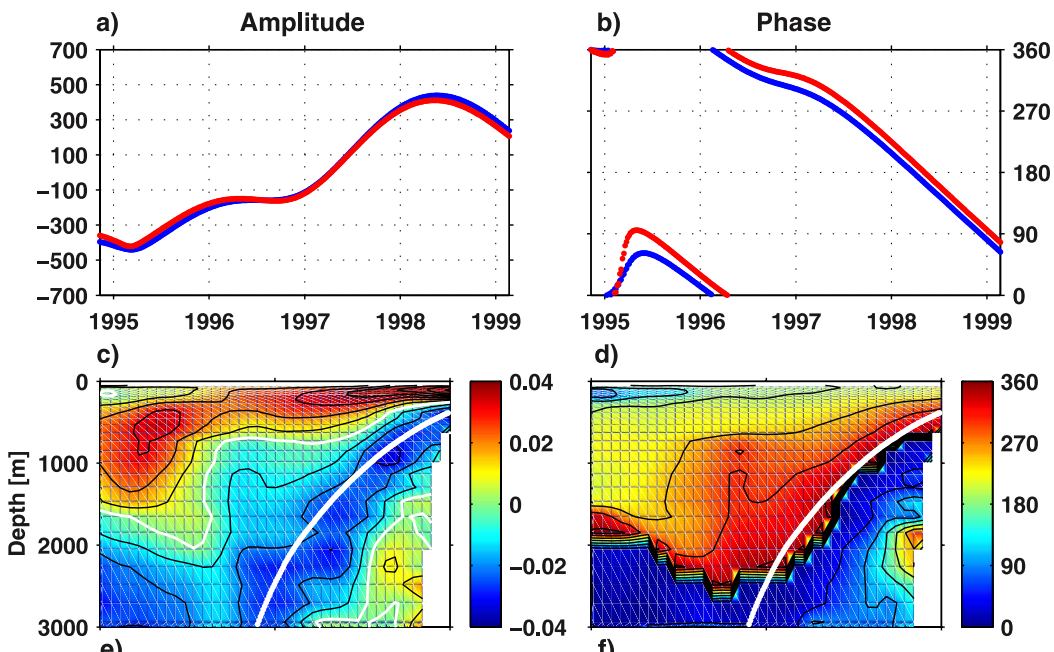

d)
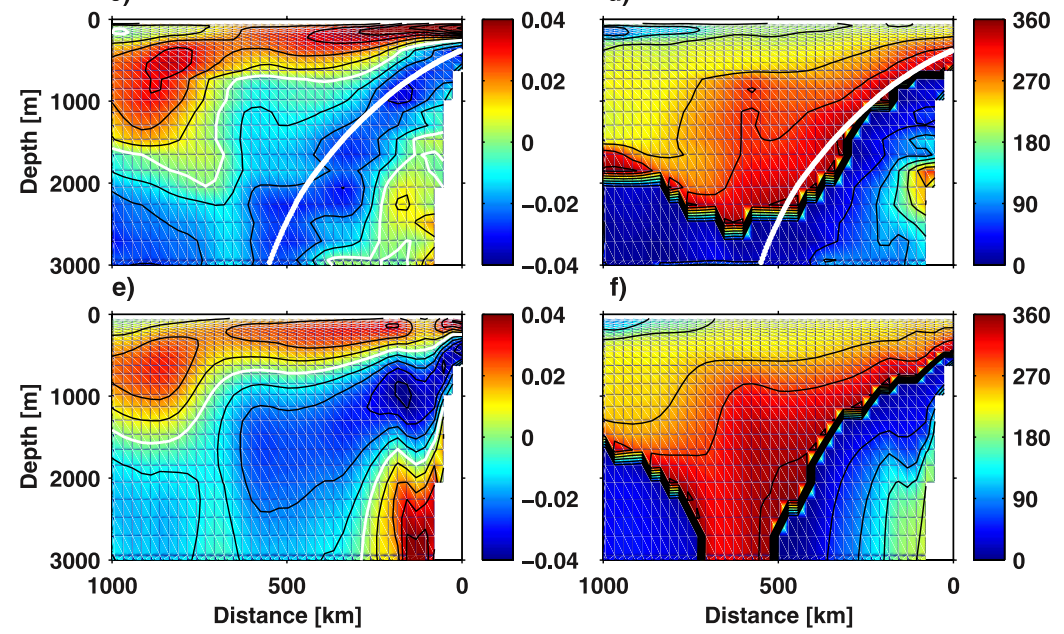

f)

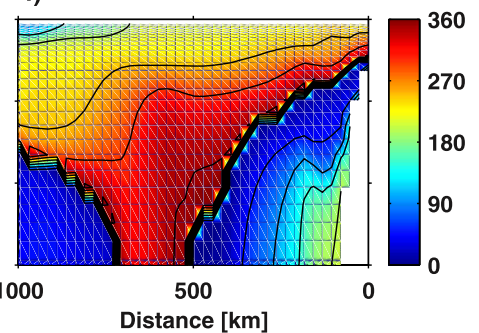

Figure 5. First CEOF mode of the interannual isotherm vertical displacements for a vertical section centered at $20^{\circ} \mathrm{S}$, based on MERCATOR model. Demeaned time series of (a) real amplitudes and (b) phases. The blue line is used for the total contribution, and the red line is used for the contribution of first three baroclinic modes. Spatial patterns of (c) real component and (d) phase for the total contribution from MERCATOR. The thick white lines indicate the theoretical raypaths of vertical propagating ETRW (see text). (e and $\mathrm{f}$ ) Same as Figures $5 \mathrm{c}$ and $5 \mathrm{~d}$ but for the contribution of the first three baroclinic modes. The amplitudes are in arbitrary units, and the phases are in degrees. Percentages of variance are explained by the first $\mathrm{CEOF}$ mode for the total contribution, and the summed-up contribution of the first three baroclinic modes are $83 \%$ and $84 \%$, respectively. 

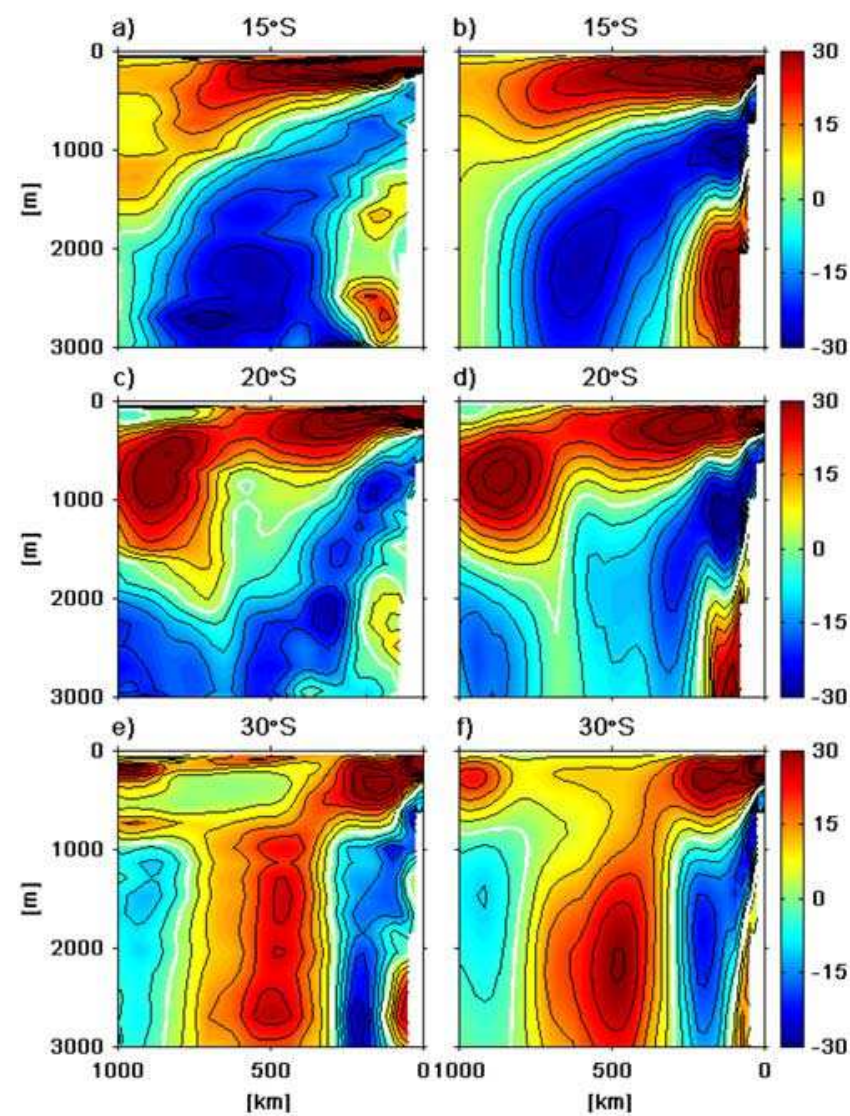

\begin{abstract}
f)
\end{abstract}

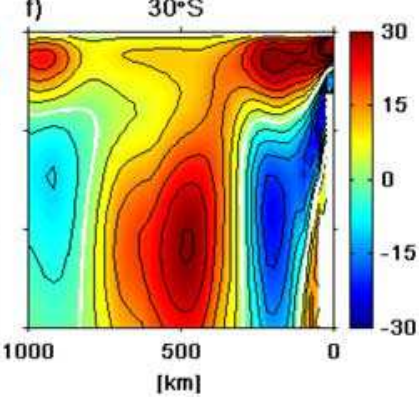

Figure 6. Sections of the isotherm vertical displacements at $15^{\circ} \mathrm{S}, 20^{\circ} \mathrm{S}$ and $30^{\circ} \mathrm{S}$, reconstructed from the first CEOF mode and estimated at the date corresponding to the maximum amplitude for sea level during the El Niño event, i.e., 1 January 1998 (see Figure 3 and text) (in m). (a, c and e) The calculation based directly on the isotherm displacements given by MERCATOR model (total contribution). (b, d and f) The calculation based on the first three baroclinic modes extracted from MERCATOR model. Percentages of variance explained by the first CEOF mode are $87 \%, 83 \%$ and $75 \%$ for the total contribution at $15^{\circ} \mathrm{S}$, $20^{\circ} \mathrm{S}$ and $30^{\circ} \mathrm{S}$, respectively. Percentages of variance explained by the first CEOF mode are 90\%, 84\% and $77 \%$ for the summed-up contribution of the first three baroclinic modes at $15^{\circ} \mathrm{S}, 20^{\circ} \mathrm{S}$ and $30^{\circ} \mathrm{S}$, respectively.

between the two products diminishes with increasing depth, in particular for the amplitude, which is due to the limited number of modes retained to recompose the signal. Note that the increase in amplitude for the "full" signal with depth is compatible with the WKB scaling, for which $\zeta$ is expected to increase as $N^{-1 / 2}$. The change in slope of the phase lines in the lower left corner of Figure $5 \mathrm{~d}$ and the increase of the amplitude (Figure 5c) there, could result from a contribution of bottom reflection.

[17] The associated temporal functions for both the "total" signal and the baroclinic mode recomposition exhibit quasi similar variability $(\mathrm{r}=0.99)$. Interestingly, they peak around March 1998 and are associated with negative amplitudes of the vertical isotherm displacements around the WKB raypath, indicating that the CEOF mode captures preferentially cool conditions in subthermocline depths during the mature phase of El Niño. Figure 6 confirms the negative amplitude of the vertical isotherm displacement in the subthermocline region at the peak of El Niño. The connection with equatorial variability and El Niño conditions along the equator will be further discussed in section 5 .

\subsubsection{Pressure and Vertical Energy Flux}

[18] Figure 7 is similar to Figure 5 but for the pressure field. Characteristics similar to the isotherm vertical displacements are encountered for the phase lines, indicating clear propagation of the variability at low frequency. The amplitude distribution shows maximum values below the thermocline in the upper $1000 \mathrm{~m}$ near the coast, and follows a WKB raypath corresponding to a frequency of $\left(1 / 3.7 \mathrm{a}^{-1}\right)$ and a phase speed value of $1.39 \mathrm{~m} \mathrm{~s}^{-1}$.

[19] To infer how much and how energy is transmitted from the surface to the deeper ocean, it is necessary to compute the vertical energy flux. By definition, raypaths should be parallel to the energy flux (cf. Appendix A) if there is no interference between the waves at various frequencies. We first compute the vertical flux through a unit horizontal area $E_{v}=\langle p . w\rangle$, where $w$ is obtained from the time derivative of the formerly derived vertical isotherm displacements and $p$ is the pressure "deviation," and the brackets refer to an adequate time average, at $15^{\circ} \mathrm{S}, 20^{\circ} \mathrm{S}$, and $30^{\circ} \mathrm{S}$ (Figure 8). Figures $8 \mathrm{a}, 8 \mathrm{c}$ and 8e show the energy fluxes estimated from the model, while Figures $8 \mathrm{~b}, 8 \mathrm{~d}$ and $8 \mathrm{f}$ show the energy fluxes estimated from the summed-up contribution of the lower 3 baroclinic modes. As mentioned in section 2, we use the CEOF dominant mode of $p$ and $w$, instead of a specific harmonic of the pressure and vertical velocity, to derive $\langle p . w\rangle$. The time averaging is done over the ENSO cycle as derived from the CEOF analysis of sea level (Figure 3). Note that similar results are obtained considering the harmonics of the 3.7-year period; however, the amplitude for the resulting flux is lower. Figure 8 indicates that some energy is transmitted through the thermocline, although this flux decreases more rapidly with depth at $30^{\circ} \mathrm{S}$ than at $15^{\circ} \mathrm{S}$. Three theoretical raypaths originating at the coast and near the surface and corresponding to the frequency $\left(1 / 3.7 \mathrm{a}^{-1}\right)$ and to the phase speed values of the first three baroclinic modes are also displayed in Figure 8. They encompass the zone of maximum energy flux (excluding the near bottom zones where local maxima are also found) below the thermocline at all the latitudes. The pattern for $\left\langle\sum_{m=1}^{3}\left(p_{m}\right) \cdot \sum_{n=1}^{3}\left(\partial \zeta_{n} / \partial t\right)\right\rangle$, where $p_{m}$ and $\zeta_{m}$ stand for the $m$ th baroclinic mode contributions to pressure and vertical displacements, respectively, exhibit similar characteristics to the "full" vertical energy flux, consistent with the interpretation of horizontal propagation of vertical standing modes.

\subsection{Connection With the Equatorial Kelvin Wave}

[20] It is now interesting to investigate the relationship between the vertically propagating variability diagnosed above and the equatorial wave activity. In order to infer the EKW amplitude, a vertical mode decomposition of the model mean equatorial stratification is sought and baroclinic mode contribution to pressure and current anomalies are derived. Projecting the results onto the theoretical Kelvin and Rossby wave structures provides an estimation of the 


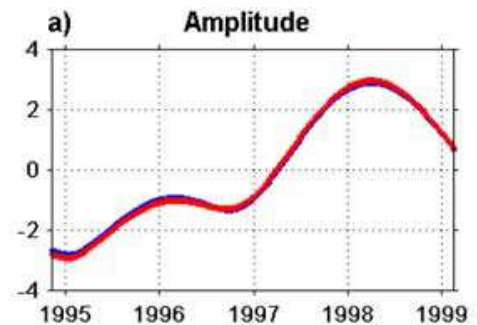

c)
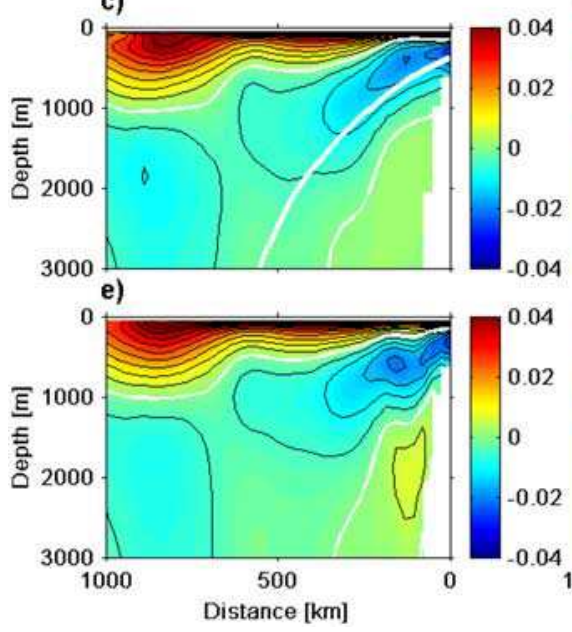

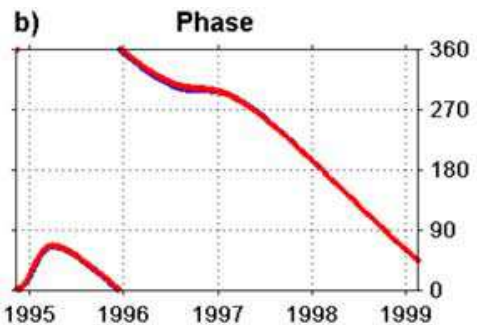

d)

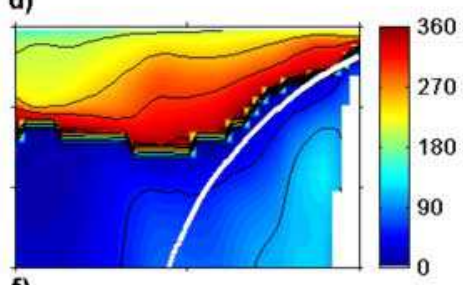

f)

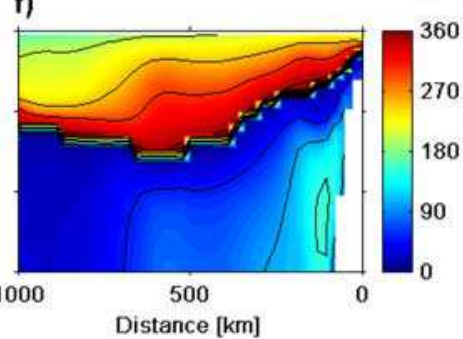

Figure 7. Similar to Figure 5 but for the pressure perturbation. In this case the percentages of variance explained by the first CEOF mode for the total contribution and the summed-up contribution of the first three baroclinic modes are $91 \%$ and $92 \%$, respectively.

equatorial wave amplitude (see Dewitte et al. [2003] for more details on the method). Consistent with the results of Dewitte et al. [2003], the most energetic Kelvin waves are found for the first 3 modes with the high-order baroclinic Kelvin wave having a larger variability in the eastern equatorial Pacific (not shown). Also, Kelvin waves of the first three modes constructively contribute to the strong warming observed in 1997, with the first (second and third) baroclinic mode(s) being more energetic than the second and third (first) baroclinic modes in the early (mature) stage of the warming (Figures 12a, 12b and 12c).

[21] The summed-up contribution of the first three baroclinic modes of the EKW is first considered for investigating the phase relationship between isotherm vertical displacements in the subthermocline at the extratropical latitudes and the equatorial variability. Figure 9 displays the dominant CEOF mode for isotherm vertical displacements along a raypath (corresponding to $\omega \sim 2 \pi / 3.7 \mathrm{a}^{-1}$ and $\mathrm{c} \sim \mathrm{c}_{2}$, see equation (A5)) at $15^{\circ} \mathrm{S}, 20^{\circ} \mathrm{S}$ and $30^{\circ} \mathrm{S}$. Consistent with Figure 5 and theory, the amplitude of the wave remains large (in absolute value) along the raypath with positive anomalies during the first half of 1997 and negative anomalies starting to grow late in 1997. Two interesting features emerge from the inspection of Figure 9:

[22] 1. The vertical displacements along the raypath are out of phase with the surface signature of the ETRW (cf. Figure 4); the minimum amplitude of the vertical displacement even takes place $\sim 5$ months after the maximum amplitude of the downwelling ETRW associated with the 1997-1998 El Niño (see Figure 4). As a consequence, the equatorial downwelling Kelvin wave associated with the 1997-1998 El Niño event (Figure 9a) is associated with the negative vertical displacement of the isotherm along the raypath.

[23] 2. The positive vertical isotherm displacement takes place prior to the mature phase of the 1997-1998 El Niño with a maximum around January-February 1997. Also noteworthy is the phase relationship between the zonal sections: the cycle at $30^{\circ} \mathrm{S}$ takes place $\sim 5$ months before the one at $15^{\circ} \mathrm{S}$ (see the zero contours on the sections to visualize the phase shift).

[24] It is worth pointing out at this stage that the $1997 \mathrm{El}$ Niño event was associated with several variability timescales for the Kelvin wave activity with particularly high-frequency wind variability that triggered downwelling Kelvin waves in the western equatorial Pacific prior to the growth of the event [McPhaden, 1999; Dewitte et al., 2003]. To illustrate this, Figure 10 presents the series of Kelvin wave amplitudes for modes 1 and 2 in the equatorial central Pacific $\left(175^{\circ} \mathrm{W}\right)$ along with the results of the wavelet analysis of these series. Highfrequency variability (10 days $<\omega^{-1}<4$ months) of the Kelvin wave clearly took place prior to the 1997 El Niño peak. Note that the "high-frequency" Kelvin wave variability has a tendency to be trapped along the coast at the critical latitude [Clarke and Shi, 1991] and that, for a given frequency, higher-order baroclinic modes result in more northern critical latitudes, which results in a complex combination of coastal-trapped wave and ETRW at the coast. In particular, the time delay between $30^{\circ} \mathrm{S}$ and $15^{\circ} \mathrm{S}$ observed in Figure 9 suggests that the high-order baroclinic modes get involved progressively as El Niño develops. This is supported by the results presented here, showing that highorder baroclinic modes (modes 2 and 3) become more energetic during the mature phase of the 1997 El Niño, 

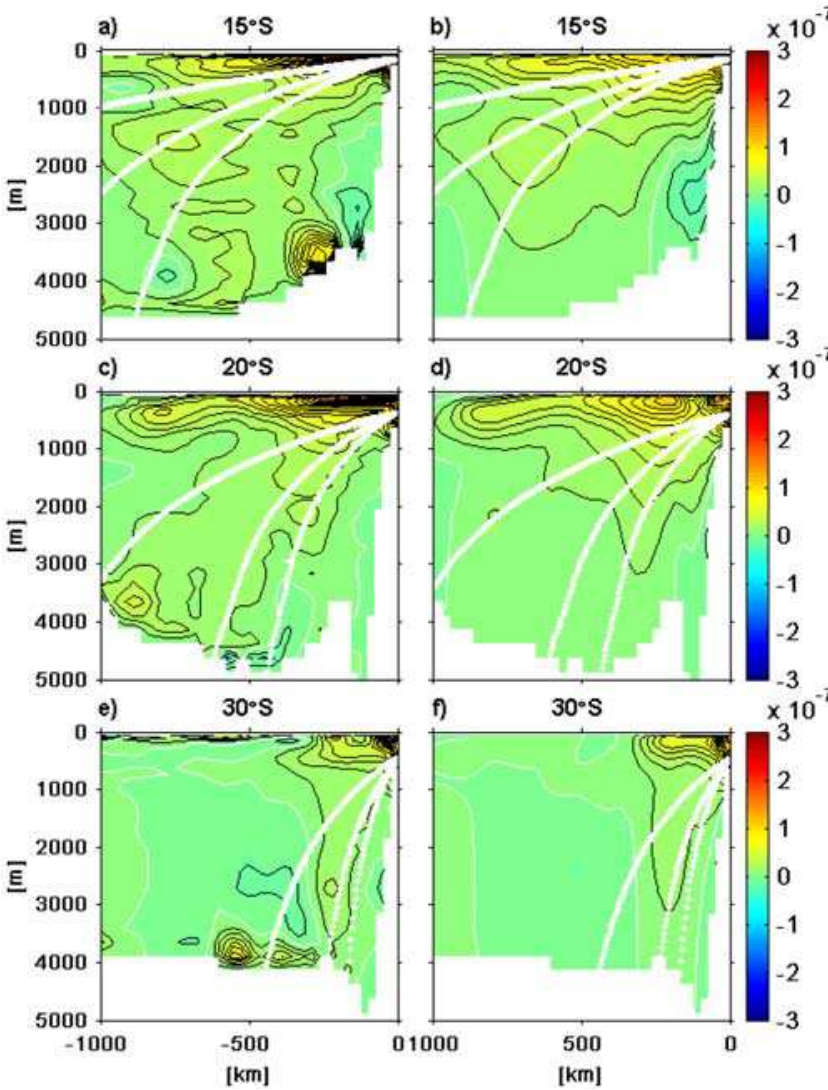

Figure 8. Sections of vertical energy flux $(<p . w\rangle)$ for the interannual signal at $15^{\circ} \mathrm{S}, 20^{\circ} \mathrm{S}$ and $30^{\circ} \mathrm{S}$ (see text) (in $\mathrm{m}^{2} \mathrm{~s}^{-2}$ ). Positive values are for downward flux. (a, c and e) Total contribution and (b, $d$ and $\mathrm{f}$ ) the summed-up contribution of the first three baroclinic modes for MERCATOR. The thick white lines indicate the theoretical raypaths for phase speed values of the first three baroclinic modes.

whereas the gravest mode is more active at the initial stage (Figures $12 \mathrm{a}, 12 \mathrm{~b}$ and $12 \mathrm{c}$ ). As a complementary analysis of the Kelvin wave activity with respect to its vertical structure, the 2-month running variance in the eastern Pacific is calculated and displayed in Figure 11. It confirms that the ratio of the gravest mode Kelvin wave amplitude versus the second or third baroclinic modes decreases with time from March 1997.

[25] The above observations lead us to detail the peculiarities of the equatorial Kelvin wave, which exhibits both rich vertical structure variability and rich temporal variability as evidenced by Figures $12 \mathrm{a}, 12 \mathrm{~b}$ and $12 \mathrm{c}$. As mentioned above, Figures $12 \mathrm{a}, 12 \mathrm{~b}$ and $12 \mathrm{c}$ reveal that (1) the equatorial Kevin waves project over the first three baroclinic modes that have a different phase speed, leading to phase lags between each other for their arrival at the eastern boundary; (2) high-order baroclinic mode equatorial Kelvin waves become more energetic as El Niño develops because of the change in the thermocline depth and vertical temperature gradients [cf. Dewitte et al., 2003] (Figure 11); and (3) Kelvin waves forced by westerly wind bursts prior to the peak phase of El Niño are present. Note, for instance, in Figure 10a, the December 1996 and March 1997 first baroclinic mode Kelvin waves in the western equatorial Pacific. These reach the eastern boundary by January 1997 and June 1997, 6 months before the peak phase of El Niño.

[26] As a consequence of the energetic higher-order EKW, the variability of isotherm vertical displacement also exhibits a rich vertical structure (Figure 12d). During the onset of the 1997 El Niño (May 1997), the first baroclinic mode dominates, leading to positive anomalies of vertical isotherm displacement over the first $1000 \mathrm{~m}$. As El Niño develops, the high-order baroclinic mode contribution increases and the response along the coast evolves as a vertical seesaw of the vertical isotherm fluctuations, with positive anomalies in the upper $500 \mathrm{~m}$ and negative anomalies below this depth between June and September 1997. As El Niño peaks in association with a rise in the amplitude of the third baroclinic mode EKW, the negative anomalies for vertical displacement spread further upward with the zero
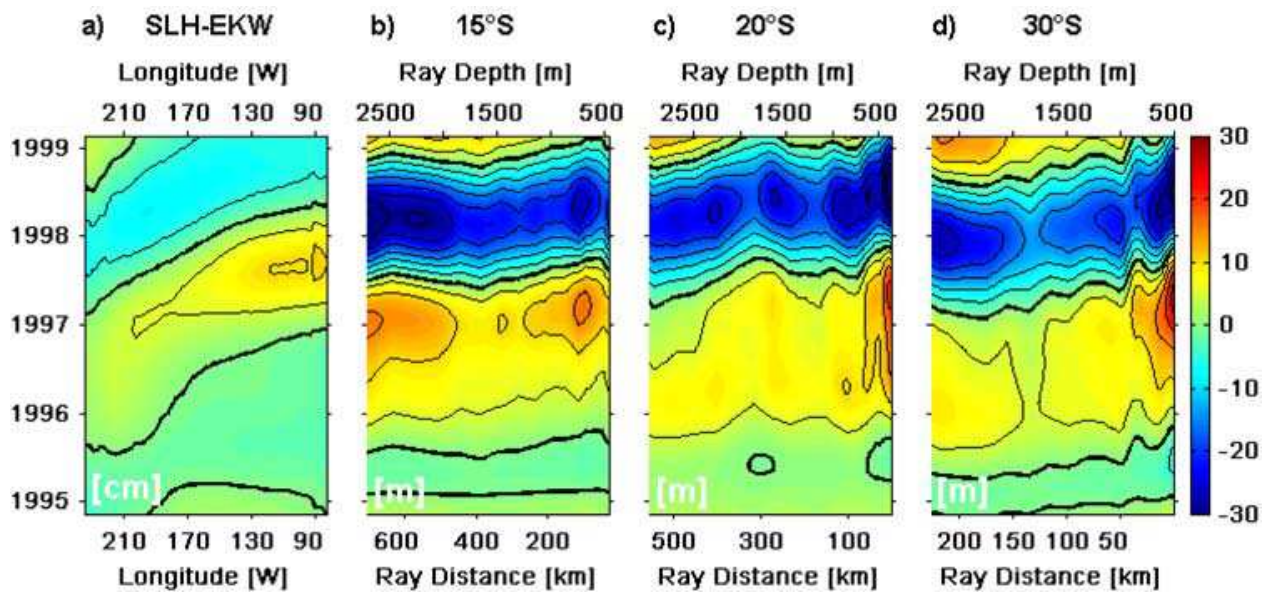

Figure 9. (a) Time-longitude plot of the summed-up contribution of the first three baroclinic modes for equatorial Kelvin waves (in $\mathrm{cm}$ ) along the equator for MERCATOR. Interannual dominant CEOF mode for isotherm vertical displacements (in $\mathrm{m}$ ) along a raypath (corresponding to $\omega=2 \pi / 3.7 \mathrm{a}^{-1}$ and $\mathrm{c} \sim \mathrm{c}_{2}$, see equation (A5)) at (b) $15^{\circ} \mathrm{S}$, (c) $20^{\circ} \mathrm{S}$ and (d) $30^{\circ} \mathrm{S}$. 

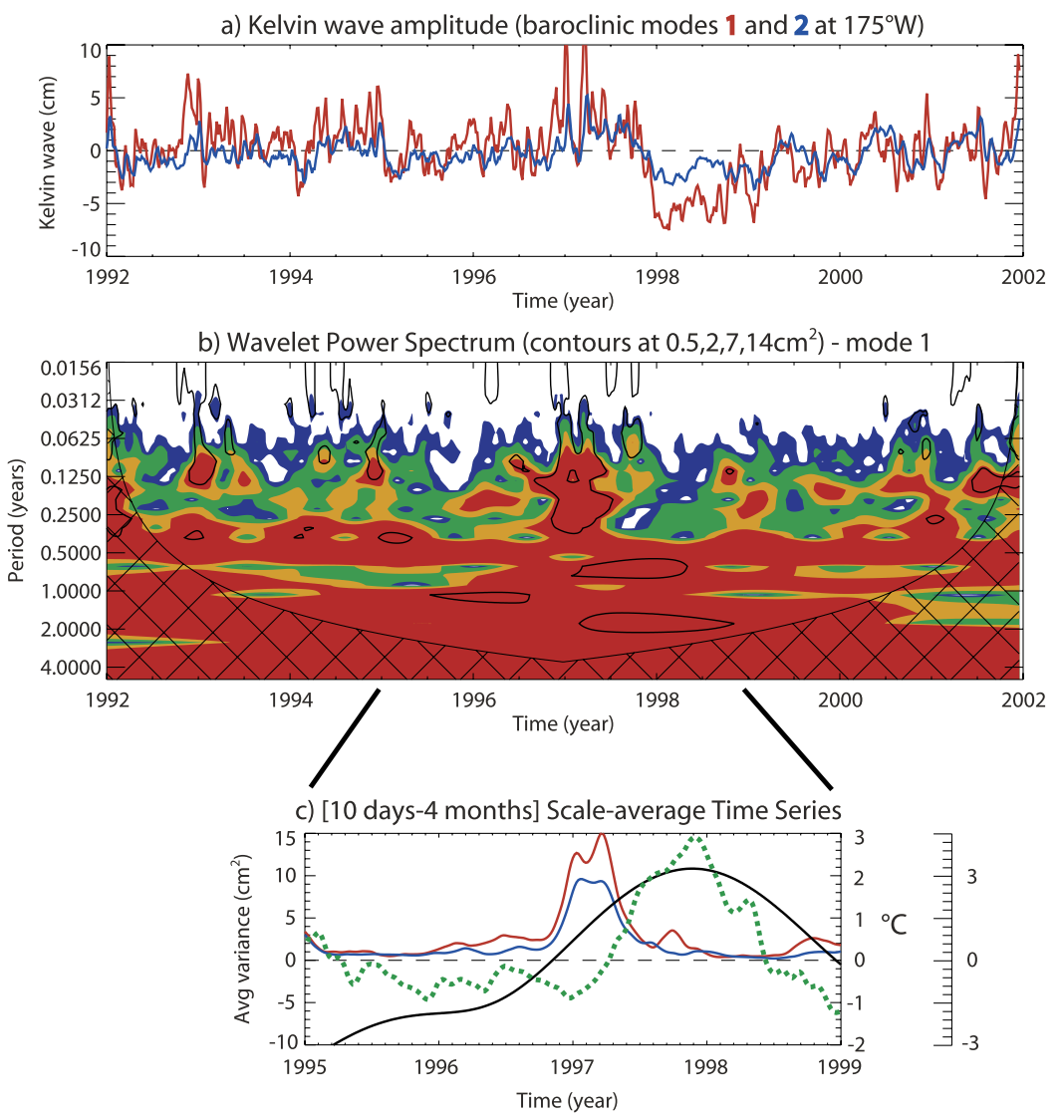

Figure 10. (a) Equatorial Kelvin wave contribution to the sea level anomalies (in $\mathrm{cm}$ ) at $175^{\circ} \mathrm{W}$. Blue line shows the contribution of mode one between 1992 and 2001. Red line shows the contribution of mode two between 1992 and 2001. (b) Wavelet spectrum for the first baroclinic mode Kelvin wave amplitude at $175^{\circ} \mathrm{W}$ using the Morlet wavelet. The thick contour is the $95 \%$ confidence level (red noise $\alpha=0.72$ ). (c) The scale-averaged wavelet power over the (10 days, 4 months) band for (blue line) first and (red line) second baroclinic Kelvin wave contribution at $175^{\circ} \mathrm{W}$ over the period $1995-1999$. The first (in $\mathrm{cm}^{2}$ ) and second (in $0.25 \times \mathrm{cm}^{2}$ ) baroclinic modes are shown in Figure 10c (left scale). The Niño3 sea surface temperature index $\left(\right.$ in ${ }^{\circ} \mathrm{C}$ ) is plotted as a dotted green line in Figure $10 \mathrm{c}$ (middle scale). The temporal function associated with the dominant CEOF mode of the summed-up contribution of modes 1 to 3 to the equatorial Kelvin wave (Figure 9a) is plotted as a black line in Figure 10c (right scale).

contour reaching $\sim 300 \mathrm{~m}$ by December 1997. As an indication of the prevailing mode contribution as a function of depth, the mean structures of the baroclinic mode are displayed in Figures $12 \mathrm{f}$ and $12 \mathrm{~g}$. These are consistent with the evolution of the vertical seesaw of isotherm vertical displacement at the coast described above, with the uppermost nodes for modes 2 and 3 located at $500 \mathrm{~m}$ and $300 \mathrm{~m}$, respectively. As the contribution of high-order baroclinic modes increases along the coast, these combine to form the WKB "beams" described in section 4.1. Figure 12e displays the time evolution at $20^{\circ} \mathrm{S}$ of the vertical isotherm displacement $522 \mathrm{~km}$ off the coast. Consistent with Figures 5 and 6, minimum amplitude is found at the depth of $\sim 2500 \mathrm{~m}$ with a maximum in January 1998. A similar sequence of the impact of the equatorial Kelvin wave is found at $15^{\circ}, 25^{\circ} \mathrm{S}$, and $30^{\circ} \mathrm{S}$ (not shown).

\section{Summary and Conclusions}

[27] The vertically propagating variability along the coast of Peru-Chile is investigated from a medium-resolution OGCM simulation focusing on the strong 1997-1998 El
Niño event. Diagnostics based on classical linear theory extended here for treating the extratropical latitudes reveal the signature of vertically propagating waves on interannual timescales along the coast. Consistent with theory, the energy "beams" associated with the interannual ETRW slope westward/downward more in the south than in the north. At $30^{\circ} \mathrm{S}$, this process is confined to the $\sim 300 \mathrm{~km}$ near the coast, which suggests that this process may be involved in the modulation of deep currents near the Chilean coast [Shaffer et al., 1995, 2004]. The analysis also reveals that the peak phase of the El Niño event along the equator is associated with negative vertical displacements of the isotherms (a rise) along the raypaths, which are due to the peculiar vertical structure variability near the coast and the impact of the higher-order baroclinic modes EKW that becomes more energetic as El Niño develops. It is interesting to note that the connection mechanism evidenced in this study between the EKW and the ETRW and associated vertical propagation may vary with the timescale under study. For instance, at a higher frequency, the change in the vertical structure of the EKW is less (because the mean 


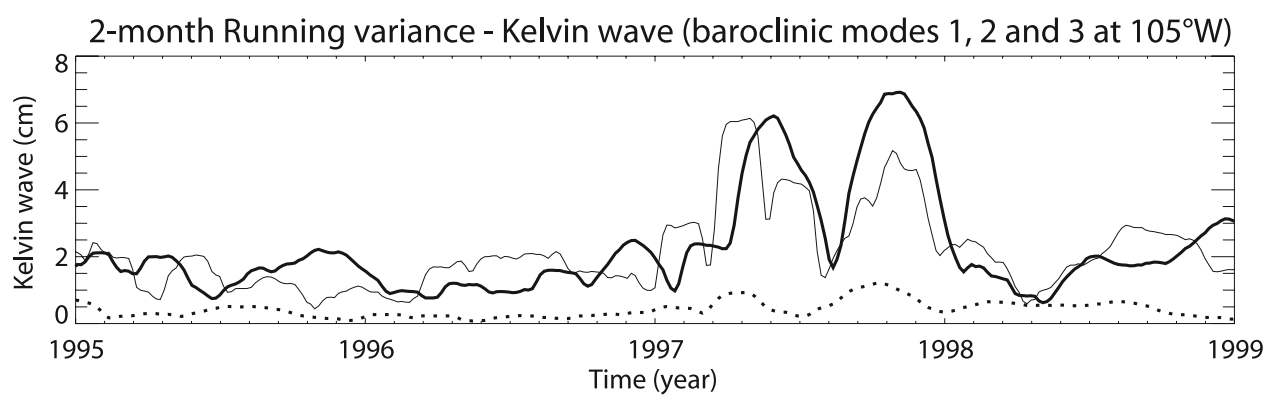

Figure 11. Two-month running variance of the equatorial Kelvin wave amplitude (in $\mathrm{cm}$ ) at $105^{\circ} \mathrm{W}$ for the (thin solid line) first, (thick solid line) second and (dotted line) third baroclinic modes over 19951999.

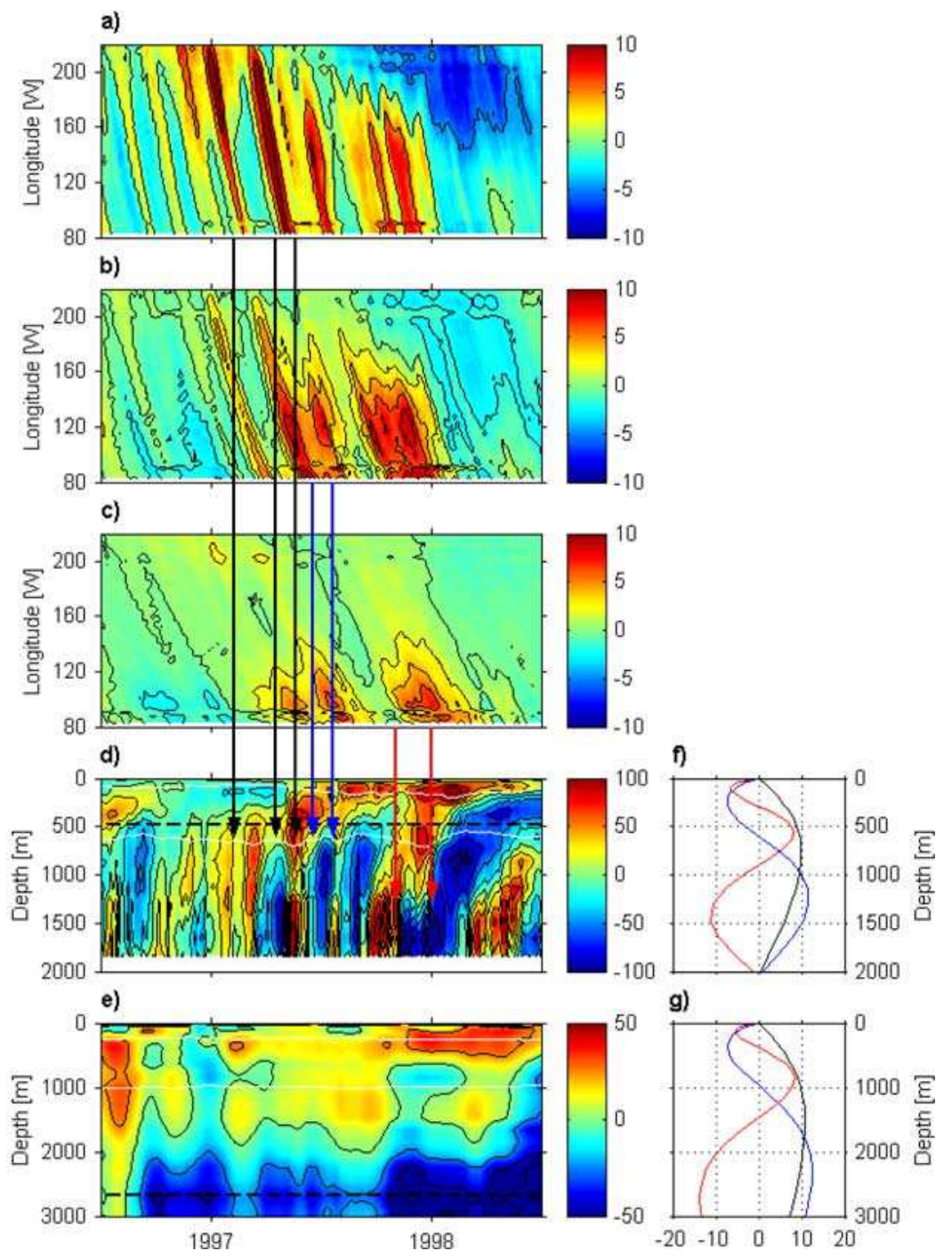

Figure 12. Longitude-time plot of the (a) first, (b) second and (c) third baroclinic mode EKW (in $\mathrm{cm}$ ) along the equator between 1 July 1996 and 1 July 1998. Isotherm vertical displacements (in m) as a function of depth at (d) $52 \mathrm{~km}$ and (e) $522 \mathrm{~km}$ from the coast at $20^{\circ} \mathrm{S}$. The white lines indicate the displacements of the mean thermocline (position of the maximum vertical mean temperature gradient and the base of the permanent thermocline). The dashed black lines stand for the depth at which the theoretical raypath (of Figure 5) intersects the sections at $52 \mathrm{~km}$ and $522 \mathrm{~km}$ offshore. The mean vertical mode functions of the first three baroclinic modes (mode 1 in black, mode 2 in blue, mode 3 in red) associated with vertical velocity are displayed for ( $\mathrm{f}$ and $\mathrm{g}$ ) the two sections. 


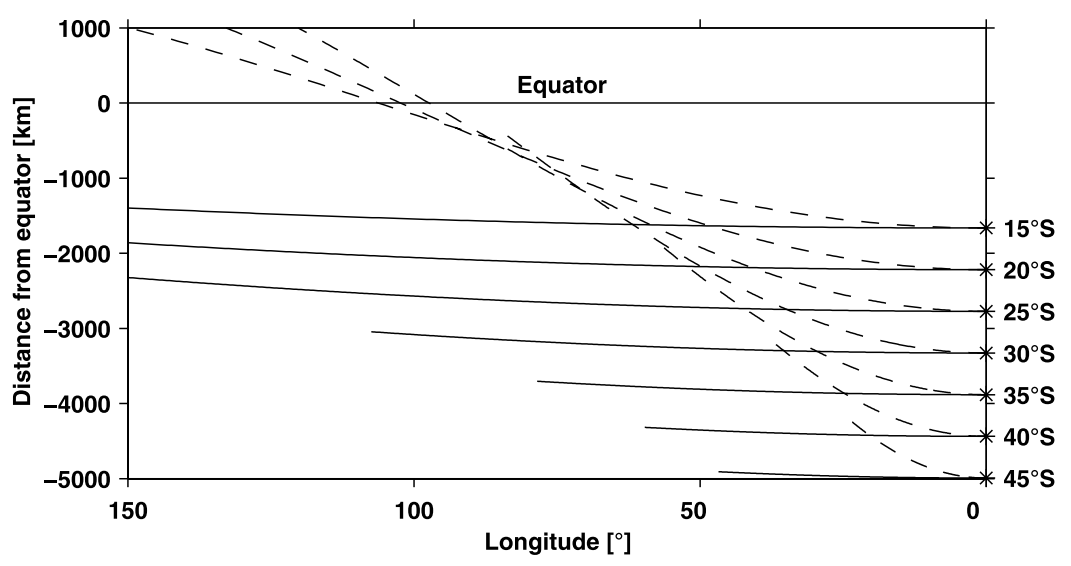

Figure A1. (continuous line) Raypaths for typical ENSO (3.7-year) period waves on the equatorial beta plane. The rays were drawn during 10 years. Note that in the domain of interest $\left(15^{\circ} \mathrm{S}-30^{\circ} \mathrm{S}\right)$, near the South American coast, rays remain approximately zonal showing small dispersion. (dashed lines) Raypath for annual period waves are also shown for comparison [cf. Schopf et al., 1981].

thermocline is less impacted) and high-order mode EKW are less energetic at the eastern boundary. This has implications for studies using the single-mode ETRW model. The one-mode linear models usually use a Rayleigh-type friction to take into account energy loss from the surface to the deep ocean. This particular approach neglects the frequency dependency, identified in our results, on the vertical propagation of energy on an interannual timescale. It also suggests that the EKW and ETRW are nonlinearly coupled; the superposition of baroclinic downwelling EKW does not necessarily result in an increased ETRW amplitude. Rather, it triggers vertical propagation of the ETRW and, consequently, modifies its surface signature, which is commonly referred to as its dissipation. It would be interesting to carry out a similar analysis focusing on other timescales of variability. In particular, at a higher frequency, the WKB raypaths are steeper and interaction with the mean coastal circulation is expected. One may wonder to what extent such processes may be involved in the variability of the Peru-Chile Undercurrent [Pizarro et al., 2002], which is a major component of the Peru-Chile Current system and spans an extended zone along the western coast of South America. Higher-resolution regional model simulations will have to be used to address this issue.

[28] We now mention limitations owed to the use of the particular simulation analyzed in this paper. First the simulation spans 10 years, which may be detrimental when researching processes on interannual timescales, and the use of the WKB to interpret the vertically propagating variability. This limitation is somehow overcome using the CEOF technique, which allows extracting a large variance of the interannual cycle despite the relatively short record. We also checked that the results presented in the paper were holding when a particular harmonic was extracted.

[29] The medium resolution of the model also results in a low level of eddy kinetic energy compared to observations (not shown). Mesoscale activity is prominent in this region [Chaigneau and Pizarro, 2005] and its impact on the vertically propagating wave depicted in this paper would need to be elucidated to fully account for the importance of such a process. Future work will be devoted to similar analyses through high-resolution model simulation. Overall, the results presented in this study illustrate the need to take into account the peculiarities of the EKW arriving at the eastern boundary, which includes its amplitude as a function of the baroclinic mode and its dominant timescale of variability, in order to interpret the surface and subsurface variability near the coast associated with ETRW propagation. It may also provide a background framework for the interpretation of observations and higher-resolution model simulations in the region.

\section{Appendix A: Linear Formalism for Vertically Propagating Extratropical Rossby Waves}

[30] As shown by Moore and Philander [1977], the linear, inviscid equations for a $\beta$-plane $\left(f=f_{0}+\beta y\right)$ can be separated into vertical and horizontal components. The horizontal component yields a dispersion relation for standing wave modes in the meridional and horizontal direction

$$
\omega=\frac{-\beta k}{k^{2}+l^{2}+f_{0}^{2} / c_{n}^{2}},
$$

where $l$ and $k$ are the meridional and zonal wave numbers, respectively, $\omega$ is the frequency, $f_{0}$ is the Coriolis parameter at some latitude $\left(\mathrm{y}_{0}\right)$, and $c_{n}$ is the separation constant of the vertical structure equation

$$
\frac{d}{d z}\left(\frac{d \Psi_{n}}{d z} N^{-2}\right)+c_{n}^{-2} \Psi_{n}=F,
$$

$N$ is the local buoyancy frequency and $F$ is the projection of the forcing. It is usually assumed to be zero below a certain depth close to the surface [Lighthill, 1969]. Thus, the vertical structure $\Psi_{n}$ is a solution of the homogeneous equation with the boundary conditions

$$
\begin{gathered}
\frac{d \Psi_{n}}{d z}+\frac{N^{2}}{g} \Psi_{n}=0 \text { at } z=0 \\
\frac{d \Psi_{n}}{d z}=0 \text { at } z=-H .
\end{gathered}
$$



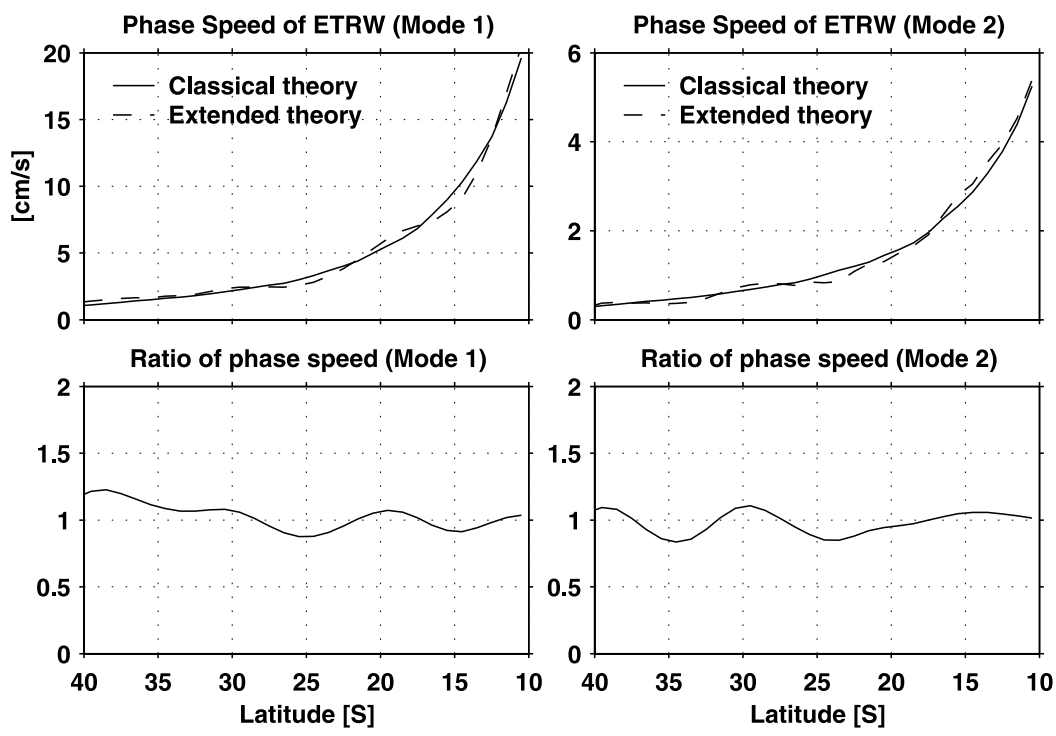

Figure A2. (top) Phase speed values (in $\mathrm{cm} \mathrm{s}^{-1}$ ) as a function of latitude near the coast (a $12^{\circ}$-width longitudinal band was considered) estimated from (solid lines) the standard theory and (dashed lines) the extended theory for the first two baroclinic modes. Extended means here considering the impact of mean flow [cf. Killworth et al., 1997]. (bottom) Ratio of the phase speed. We can see that in the studied area $\left(15^{\circ} \mathrm{S}-30^{\circ} \mathrm{S}\right)$, the background mean flow has little impact on the estimation of phase speed (deviation from standard theory is less than $12 \%$ for both modes).

From the vertical equation (A2), a local vertical wave number can be defined

$$
m_{n}(x, z)=\frac{N(x, z)}{c_{n}(x)}
$$

where $x$ and $z$ are the horizontal and vertical coordinates, respectively. We now consider a motion which is the combination of the solutions of the different vertical modes for a specified $m$, the local vertical wave number. It is then interesting to describe the solution as if the vertical scale $m^{-1}$ of the wave was small compared with the scale on which $m$ varies (WKB approximation). Equation (A1) is then a relationship between $\omega, m$, and $k$ which can be differentiated to estimate group velocities. In this study, we consider only long zonal wavelengths. In this limit $\left(k^{2}+\right.$ $l^{2} \approx 0$ ), the dispersion relationship reduces to

$$
\omega=-\frac{\beta k c_{n}^{2}}{f_{0}^{2}} .
$$

Given the wave frequency and phase speed, the trajectory that defines the wave energy propagation can be obtained by integrating two simple differential equations

$$
\frac{d x}{d t}=C_{n g}^{x}=\frac{\partial \omega}{\partial k} \text { and } \frac{d z}{d t}=C_{n g}^{z}=\frac{\partial \omega}{\partial m}
$$

The slope of raypaths in the $(\mathrm{x}, \mathrm{z})$ plane becomes

$$
\frac{d z}{d x}=\frac{c_{g}^{z}}{c_{g}^{x}}=2 \frac{\omega f^{2}}{\beta c N}
$$

Therefore, the wave energy originating at the surface propagates downward toward the west with a steeper slope for weaker stratification or lower latitude. With the definition of the phase propagation in the zonal and vertical directions, and because the wave is nondispersive in the long zonal wavelength limit, phase lines are parallel to WKB raypaths. This wave propagation provides a mechanism by which low-frequency energy generated by surface wind is transmitted into the deep extratropical ocean.

[31] The assumption that the wave can be considered nondispersive (by linear beta dispersion) is justified by the theoretical results of Schopf et al. [1981] applied to the case of interannual timescale (see Figure A1). In particular, at the $3.7 \mathrm{a}^{-1}$ period, there is no caustic for the WKB rays in the region of interest. On the other hand, effects of the mean zonal baroclinic flow in the domain of interest, estimated from the model simulation, showed that the mean current is rather weak $\left(<0.5 \mathrm{~cm} \mathrm{~s}^{-1}\right.$ below the surface Ekman layer) and they neither affect significantly the gradient of the mean potential vorticity nor the properties of the long Rossby wave [e.g., Yang, 2000]. We also evaluated the effect of the observed mean baroclinic zonal flow on the vertical mode structure and the associated phase speed. For the first two modes the vertical mode structures remain similar and changes in the phase speed are small as illustrated by Figure A2, which shows values for phase speed calculated with the standard and extended theory [cf. Killworth et al., 1997].

[32] Acknowledgments. M. Ramos was supported by a scholarship and a thesis scholarship (AT-4040200) from the Chilean National Research Council (CONICYT) and during 2007 by CEAZA Center. The preparation and development of this work were made possible thanks to several stays at PROFC and LEGOS (B. Dewitte, O. Pizarro, and M. Ramos) funded by ECOS (grant C03U05). M. Ramos and O. Pizarro are grateful for support from FONDECYT grant 1080606. O. Pizarro is grateful for support from CONICYT (PBCT-ACT 19 and FONDAP/COPAS). B. Dewitte and O. Pizarro are also grateful from ANR/France Support. The authors would like to thank Aldo Montecinos for his contribution in the use of the CEOF 
method and Jeffrey Blundell, who has kindly provided us with the program to compute the extended theory for the Rossby waves.

\section{References}

Boyer, T., S. Levitus, H. Garcia, R. Locarnini, C. Stephens, and J. Antonov (2005), Objective analyses of annual, seasonal, and monthly temperature and salinity for the World Ocean on a $0.25^{\circ}$ grid, Int. J. Climatol., 25, 931-945, doi:10.1002/joc. 1173.

Chaigneau, A., and O. Pizarro (2005), Mean surface circulation and mesoscale turbulent flow characteristics in the eastern South Pacific, from satellite tracked drifters, J. Geophys. Res., 110, C05014, doi:10.1029/ 2004JC002628.

Chelton, D., and M. Schlax (1996), Global observations of oceanic Rossby waves, Science, 272, 234-238, doi:10.1126/science.272.5259.234

Cipollini, P., D. Cromwell, G. Quartly, and P. Challenor (2000), Remote sensing of oceanic extratropical Rossby waves, in Satellites, Oceanography and Society, edited by D. Halpern, pp. 99-123, Elsevier, New York. Clarke, A., and C. Shi (1991), Critical frequencies at ocean boundaries, J. Geophys. Res., 96, 10,731-10,738, doi:10.1029/91JC00933.

Colin deVerdiere, A., and R. Tailleux (2005), The interaction of a baroclinic mean flow with long Rossby waves, J. Phys. Oceanogr. 35, 865-879, doi:10.1175/JPO2712.1.

Derval, C., E. Durand, G. Garric, and E. Remy (2005), Dossier d'expérimentation, Rep. ORCA-R025 POG05B, Projet MERCATOR, Toulouse, France.

deSzoeke, R., and D. Chelton (1999), The modification of long planetary waves by homogeneous potential vorticity layers, J. Phys. Oceanogr., 29 500-511, doi:10.1175/1520-0485(1999)029<0500:TMOLPW >2.0.CO;2.

Dewitte, B., and G. Reverdin (2000), Vertically propagating annual and interannual variability in an OGCM simulation of the tropical Pacific ocean in 1985-94, J. Phys. Oceanogr., 30, 1562-1581, doi:10.1175/ 1520-0485(2000)030<1562:VPAAIV >2.0.CO;2.

Dewitte, B., G. Reverdin, and C. Maes (1999), Vertical structure of an OGCM simulation of the equatorial Pacific Ocean in 1985-1994, J. Phys. Oceanogr., 29, 1542-1570, doi:10.1175/1520-0485(1999) $029<1542$ :VSOAOS $>2.0 . \mathrm{CO} ; 2$.

Dewitte, B., S. Illig, L. Parent, Y. duPenhoat, L. Gourdeau, and J. Verron (2003), Tropical Pacific baroclinic mode contribution and associated long waves for the 1994-1999 period from an assimilation experiment with altimetric data, J. Geophys. Res., 108(C4), 3121, doi:10.1029/ 2002JC001362.

Dewitte, B., M. Ramos, V. Echevin, O. Pizarro, and Y. duPenhoat (2008), Vertical structure variability in a seasonal simulation of a mediumresolution regional model simulation of the south eastern Pacific, Prog. Oceanogr., in press.

Ducet, N., P. Le Traon, and G. Reverdin (2000), Global high resolution mapping of ocean circulation from Topex/Poseidon and ERS-1/2, J. Geophys. Res., 105, 19,477-19,498, doi:10.1029/2000JC900063.

Eliassen, A., and E. Palm (1960), On the transfer of energy in stationary mountain waves, Geofys. Publ., 22(3), 1-23.

Fu, L., and D. Chelton (2001), Large-scale ocean circulation, in Satellite Altimetry and Earth Sciences, edited by L.-L. Fu and A. Cazenave, pp. 133-169, Elsevier, London.

Gent, P., and J. Luyten (1985), How much energy propagates vertically in the equatorial oceans?, J. Phys. Oceanogr., 15, 997-1007, doi:10.1175/ 1520-0485(1985)015<0997:HMEPVI >2.0.CO;2.

Horel, J. (1984), Complex principal component analysis: Theory and examples, J. Clim. Appl. Meteorol., 23, 1660-1673, doi:10.1175/ 1520-0450(1984)023<1660:CPCATA >2.0.CO;2.

Jakobsson, M., N. Cherkis, J. Woodward, R. Macnab, and B. Coakley (2000), New grid of Arctic bathymetry aids scientists and mapmakers, Eos Trans. $A G U, 81(9), 89$, doi:10.1029/00EO00059.

Jones, S. (1978), Rossby wave interactions and instabilities in a rotating two-layer fluid on a beta-plane. Part I. Resonant interactions, Geophys. Astrophys. Fluid Dyn., 11, 289-322, doi:10.1080/03091927808242671.

Jourdan, D., E. Balopoulos, M. Garcia-Fernandez, and C. Maillard (1998), Objective analysis of temperature and salinity historical data set over the Mediterranean basin, paper presented at OCEANS '98 Conf., Nice, France.

Kessler, W., and J. McCreary (1993), The annual wind-driven Rossby wave in the subthermocline equatorial Pacific, J. Phys. Oceanogr., 23, $1192-$ 1207, doi:10.1175/1520-0485(1993)023<1192:TAWDRW $>2.0 . C O ; 2$.

Killworth, P., and J. Blundell (1999), The effect of bottom topography on the speed of long extratropical planetary waves, J. Phys. Oceanogr., 29 , 2689-2710, doi:10.1175/1520-0485(1999)029<2689:TEOBTO $>2$.0. $\mathrm{CO} ; 2$.

Killworth, P., and J. Blundell (2004), The dispersion relation for planetary waves in the presence of mean flow and topography. Part I: Analytical theory and one-dimensional examples, J. Phys. Oceanogr., 34, $2692-$ 2711, doi:10.1175/JPO2635.1.
Killworth, P., D. Chelton, and R. de Szoeke (1997), The speed of observed and theoretical long extratropical planetary waves, J. Phys. Oceanogr. 27, 1946-1966, doi:10.1175/1520-0485(1997)027<1946: TSOOAT $>2.0 . \mathrm{CO} ; 2$

LaCasce, J., and J. Pedlosky (2004), The instability of Rossby basin modes and oceanic eddy field, J. Phys. Oceanogr., 34, 2027-2041, doi:10.1175/ 1520-0485(2004)034<2027:TIORBM >2.0.CO;2.

Leonardi, A., S. Morey, and J. O'Brien (2002), Interannual variability in the eastern subtropical North Pacific Ocean, J. Phys. Oceanogr., 32, $1824-$ 1837, doi:10.1175/1520-0485(2002)032<1824:IVITES $>2.0$ CO 2

Levitus, S., T. Boyer, M. Conkright, T. O’Brian, J. Antonov, C. Stephens, L. Stathopolos, D. Johnson, and R. Gelfeld (1998), World Ocean Database 1998, vol. 1, Introduction, NOAA Atlas NESDIS, vol. 18, NOAA, Silver Spring, Md.

Lighthill, M. (1969), Dynamical response of the Indian Ocean to the onset of the southwest monsoon, Philos. Trans. R. Soc. London, Ser. A, 265, 45-92, doi:10.1098/rsta.1969.0040.

Lythe, M., D. Vaughan, and B. Consortium (2001), BEDMAP: A new ice thickness and subglacial topographic model of Antarctica, J. Geophys. Res., 106, 11,335-11,352, doi:10.1029/2000JB900449.

Madec, G., and M. Imbard (1996), A global ocean mesh to overcome the North Pole singularity, Clim. Dyn., 12, 381-388, doi:10.1007/BF00211684.

Madec, G., P. Delecluse, M. Imbard, and C. Levy (1998), OPA 8.1 general circulation model reference manual, Note 11, 91 pp., Inst. Pierre-Simon Laplace, Univ. Pierre et Marie Curie, Paris

McCreary, J. (1984), Equatorial beams, J. Mar. Res., 42, 395-430.

McPhaden, M. (1999), Genesis and evolution of the 1997-1998 El Niño, Science, 283, 950-954, doi:10.1126/science.283.5404.950.

Montecinos, A., O. Leth, and O. Pizarro (2007), Wind-driven interdecadal variability in the eastern South Pacific, J. Geophys. Res., 112, C04019, doi:10.1029/2006JC003571.

Moore, D., and S. Philander (1977), Modelling the tropical ocean circulation, Sea, 6, 319-361.

Pizarro, O., A. Clarke, and S. Van Gorder (2001), El Niño sea level and current along the South American coast: Comparison of observations with theory, J. Phys. Oceanogr., 31, 1891-1903, doi:10.1175/15200485(2001)031<1891:ENOSLA>2.0.CO;2.

Pizarro, O., G. Shaffer, B. Dewitte, and M. Ramos (2002), Dynamics of seasonal and interannual variability of the Peru-Chile Undercurrent, Geophys. Res. Lett., 29(12), 1581, doi:10.1029/2002GL014790.

Qiu, B., W. Miao, and P. Müller (1997), Propagation and decay of forced and free baroclinic Rossby waves in off-equatorial oceans, J. Phys. Oceanogr., 27, 2405-2417.

Ramos, M., O. Pizarro, L. Bravo, and B. Dewitte (2006), Seasonal variability of the permanent thermocline off northern Chile, Geophys. Res. Lett., 33, L09608, doi:10.1029/2006GL025882.

Schopf, P., D. Anderson, and R. Smith (1981), Beta-dispersion of lowfrequency Rossby waves, Dyn. Atmos. Oceans, 5, 187-214 doi:10.1016/0377-0265(81)90011-7.

Shaffer, G., S. Salinas, O. Pizarro, A. Vega, and S. Hormazábal (1995), Currents in the deep ocean off Chile, Deep Sea Res., Part I, 42, 425-436, doi:10.1016/0967-0637(95)99823-6.

Shaffer, G., O. Pizarro, L. Djurfeldt, S. Salinas, and J. Rutllant (1997), Circulation and low-frequency variability near the Chilean coast: Remotely forced fluctuations during the 1991-92 El Niño, J. Phys. Oceanogr., 27, 217-235, doi:10.1175/1520-0485(1997)027<0217:CALFVN $>2.0$. $\mathrm{CO} ; 2$.

Shaffer, G., S. Hormazabal, O. Pizarro, and S. Salinas (1999), Seasonal and interannual variability of currents and temperature off central Chile, $J$. Geophys. Res., 104, 29,951-29,962, doi:10.1029/1999JC900253.

Shaffer, G., S. Hormazabal, O. Pizarro, and M. Ramos (2004), Circulation and variability in the Chile Basin, Deep Sea Res., Part I, 51, 1367-1386, doi:10.1016/j.dsr.2004.05.006.

Smith, W., and D. Sandwell (1997), Global sea-floor topography from satellite altimetry and ship depth soundings, Science, 277, 1956-1962, doi:10.1126/science. 277.5334 .1956

Stammer, D. (1997), Global characteristics of ocean variability estimated from regional TOPEX/POSEIDON altimeter measurements, J. Phys. Oceanogr., 27, 1743-1769, doi:10.1175/1520-0485(1997)027 $<1743$ :GCOOVE $>2.0 . \mathrm{CO} ; 2$.

Steele, M., R. Morley, and W. Ermold (2001), PHC: A global ocean hydrographic with a high quality Arctic Ocean, J. Clim., 14, 2079-2087, doi:10.1175/1520-0442(2001)014<2079:PAGOHW>2.0.CO;2.

Tailleux, R. (2004), A WKB analysis of surface signature and vertical structure of long extratropical baroclinic Rossby waves over topography, Ocean Modell., 6, 191-219, doi:10.1016/S1463-5003(02)00065-3.

Tailleux, R., and J. McWilliams (2001), The effect of bottom pressure decoupling on the speed of extratropical baroclinic Rossby waves, J. Phys. Oceanogr., 31, 1461-1476, doi:10.1175/1520-0485(2001)031<1461:TEOBPD>2.0.$\mathrm{CO} ; 2$. 
Tailleux, R., and J. McWilliams (2002), Energy propagation of long extratropical Rossby waves over slowly varying zonal topography, J. Fluid Mech., 473, 295-319, doi:10.1017/S0022112002002422.

Uppala, S., et al. (2005), The ERA-40 re-analysis, Q.J.R. Meteorol. Soc., 131, 2961-3012, doi:10.1256/qj.04.176.

Vega, A., Y. duPenhoat, B. Dewitte, and O. Pizarro (2003), Equatorial forcing of interannual Rossby waves in the eastern South Pacific, Geophys. Res. Lett., 30(5), 1197, doi:10.1029/2002GL015886.

Wang, L., C. Koblinsky, S. Howden, and B. Becley (1998), Large-scale Rossby wave in the mid-latitude South Pacific from altimetry data, Geophys. Res. Lett., 25, 179-182, doi:10.1029/97GL03567.

White, W. (2000), Tropical coupled Rossby waves in the Pacific Oceanatmosphere system, J. Phys. Oceanogr., 30, 1245-1264, doi:10.1175/ 1520-0485(2000)030<1245:TCRWIT $>2.0$. CO 2 .

White, W., Y. Chao, and C.-K. Tai (1998), Coupling of biennial oceanic Rossby waves with the overlying atmosphere in the Pacific basin,
J. Phys. Oceanogr., 28, 1236-1251, doi:10.1175/15200485(1998)028<1236:COBORW $>2.0 . C O ; 2$.

Yang, H. (2000), Evolution of long planetary wave packets in a continuously stratified ocean, J. Phys. Oceanogr., 30, 2111-2123, doi:10.1175/ 1520-0485(2000)030<2111:EOLPWP > 2.0.CO;2.

B. Dewitte, LEGOS, 14 Avenue Edouard Belin, Toulouse F-31400, France.

G. Garric, MERCATOR-OCEAN, Parc Technologique du Canal 8-10 Rue Hermès, Ramonville St. Agne F-31520, France.

O. Pizarro, Departamento de Geofísica, Universidad de Concepción, Casilla 160-C, Concepción, Chile.

M. Ramos, Centro de Estudios Avanzados en Zonas Áridas, Facultad de Ciencias del Mar, Universidad Católica del Norte, Larrondo 1281, Casilla 117, Coquimbo, Chile. (marcel.ramos@ceaza.cl) 